\title{
The Evaluation of Emotion Regulation in Caregivers Referred to a Parent-Training Program
}

Nancy M. Wallace

West Virginia University

Follow this and additional works at: https://researchrepository.wvu.edu/etd

\section{Recommended Citation}

Wallace, Nancy M., "The Evaluation of Emotion Regulation in Caregivers Referred to a Parent-Training Program" (2014). Graduate Theses, Dissertations, and Problem Reports. 248.

https://researchrepository.wvu.edu/etd/248

This Thesis is protected by copyright and/or related rights. It has been brought to you by the The Research Repository @ WVU with permission from the rights-holder(s). You are free to use this Thesis in any way that is permitted by the copyright and related rights legislation that applies to your use. For other uses you must obtain permission from the rights-holder(s) directly, unless additional rights are indicated by a Creative Commons license in the record and/ or on the work itself. This Thesis has been accepted for inclusion in WVU Graduate Theses, Dissertations, and Problem Reports collection by an authorized administrator of The Research Repository @ WVU. For more information, please contact researchrepository@mail.wvu.edu. 
The Evaluation of Emotion Regulation in Caregivers Referred to a Parent-Training Program Nancy M. Wallace, B.A.

Thesis defense submitted to the Eberly College of Arts and Sciences

at West Virginia University in partial fulfillment of the requirements

for the degree of

Master of Science

in

Psychology

Cheryl B. McNeil, Ph.D., Chair

Elisa Krackow, Ph.D.

Amy Gentzler, Ph.D.

Department of Psychology

Morgantown, West Virginia

2014

Keywords: Disruptive Behavior, PCIT, Emotion Regulation, Parenting Copyright 2014 Nancy M. Wallace 


\begin{abstract}
The Evaluation of Emotion Regulation in Caregivers Referred to a Parent-Training Program
\end{abstract}

Nancy M. Wallace

In recent years, emotion regulation has become a topic of particular interest to both clinicians and researchers and has been shown to play a significant role in a variety of behavioral and psychological difficulties in both adults and children (Gratz \& Tull, in press). However, parents of children referred for parent training may experience significant difficulty regulating their emotions as they attempt to cope with and control their children's misbehavior. The present study explored the role of caregiver emotion regulation in parent training by attempting to understand if (1) parents and children who are referred for parent training have difficulty with emotion regulation, and (2) recognize the degree to which these difficulties correlate with levels of negative interactions, parental stress, children's behavior problems and children's emotion regulation at the beginning of treatment. Parents of children referred for parent training completed self-report measures of caregiver and child emotion regulation, child behavior problems and parenting stress. Caregiver-child interactions were assessed in three structured play situations in which the frequency of caregiver negative speech and child compliance were coded. Two one sample t-tests followed by a series of bivariate analyses and two multiple regressions were conducted. The current sample of caregivers was not found to be more emotionally dysregulated than a non-referred sample of adults. However, the current sample of children was found to display more negative emotions, possess greater emotional lability $(\mathrm{t}(31)=6.562, \mathrm{p}=$ $.104)$ and demonstrate less emotion regulation $(\mathrm{t}(31)=-3.684, \mathrm{p}=.001)$ as compared to a typical sample of children. Caregiver emotion dysregulation was not found to significantly correlate with caregiver negative talk across all three DPICS situations. However, caregiver emotion dysregulation was found to be positively and significantly correlated with caregiver overall stress $(\mathrm{r}=.654, \mathrm{p}=.000)$, and total child disruptive behavior problems $(\mathrm{r}=.512, \mathrm{p}=$ .003 ). Caregiver emotion dysregulation was not significantly correlated with the frequency of caregiver negative speech or behavioral observations of child compliance. Caregiver emotion dysregulation was not significantly correlated with child emotion regulation. In two multiple regression analyses, parental distress emerged as the only significant predictor of caregiver emotion regulation, while two separate measures of child behavior problems emerged as the only significant predictor of child emotion regulation. Limitations, and suggestions for future research are discussed. 


\section{Table of Contents}

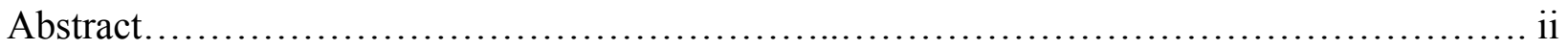

Table of

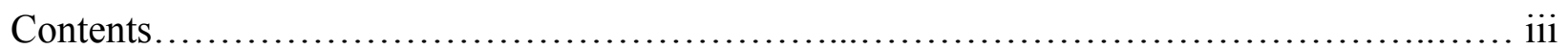

LIST OF

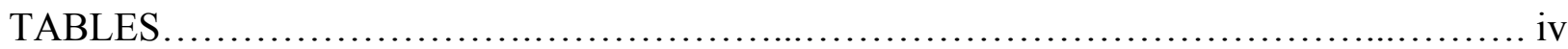

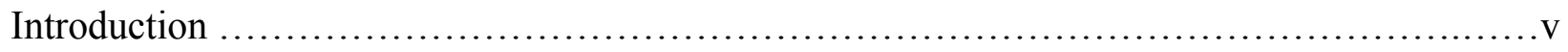

Hypotheses................................................................ 30

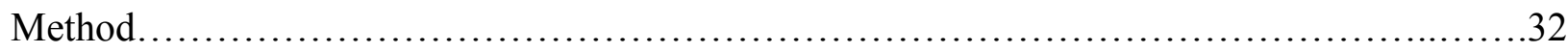

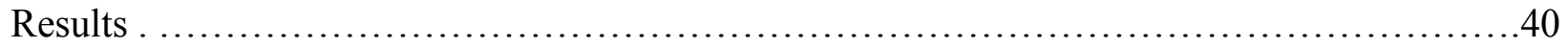

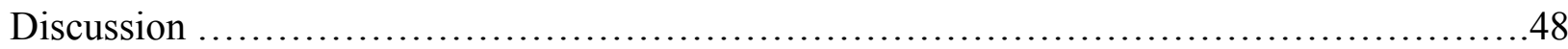

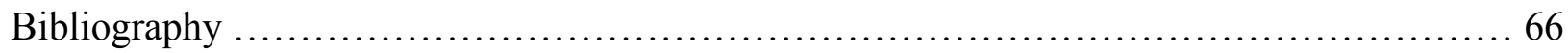

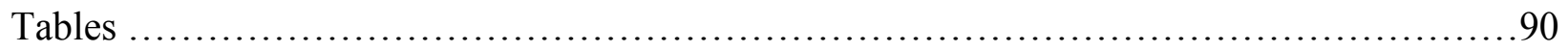


Table 1: Means and Standard Deviations for Caregiver, Child Age and Family Income

Table 2: Count of Caregiver Marital Status.

Table 3: Count of Caregiver and Child Sex and Race...

Table 4: Count of Highest Caregiver Educational Level Achieved...

Table 5: Means and Standard Deviations for Emotion Regulation Measures in a Non-Referred Comparison Adult Sample, Non-Referred Comparison Child Sample and Current Sample of Caregivers and Children.

Table 6: Results of One-sample t-test for Emotion Regulation Measures

Table 7: Means and Standard Deviations for Parent Measures Total Scores and Subscale Scores

Table 8: Correlations between DERS Total Score and PSI Total and Subscale Scores.....

Table 9: Correlations between DERS total score and CBCL Subscale Scores

Table 10: Correlations between DERS total score and ECBI Subscale Scores

Table 11: Correlation between DERS total score and ERC Total Score

Table 12: Summary of Linear Multiple Regression Analysis Predicting Caregiver Emotion Dysregulation (DERS)

Table 13: Summary of Linear Multiple Regression Analysis Predicting Child Emotion Regulation (ERC)

Table 14: Correlational Matrix between all Total Scores. 


\section{Introduction}

In recent years, emotion regulation has become a topic of considerable interest as its influence has been shown to significantly affect a variety of psychological and behavioral difficulties. Emotion regulation may help explain the core difficulties of those suffering from mood, anxiety, and behavioral disorders as well as underlie maladaptive behaviors such as cutting and hair pulling (Gratz \& Tull, in press). The development of emotion regulatory skills begins in early childhood when infants rely upon their caregivers to recognize and respond to emotional cues. As children develop, they must learn to regulate the form and intensity of their emotions in the context of the particular environment. In adulthood, successful emotion regulation is critical to adaptive social and emotional functioning in personal and professional environments as well as in the role of a parent. Emotion regulation has been correlated with early academic achievement (Graziano, Reavis, Keane, \& Calkins, 2007), social competence, and a variety of social skills, indicating its influence in a variety of domains (Davidov \& Grusec, 2006; Denham, Mitchell-Copeland, Strandberg, Auerbach, \& Blair, 1997).

In a recent longitudinal study, Moffitt and colleagues (2010) followed a cohort of 1,000 children from birth to age 32 and found that childhood self-control, including the ability to control one's emotional expression, predicted physical health, substance use, personal finances, and criminal offending outcomes years later. Such effects remained even after researchers separated the effects of the children's self-control from the individuals' intelligence levels and social class. Researchers also examined the impact of mistakes made as adolescents (e.g., early smoking, school drop-out, unplanned pregnancy) and found that when such effects were partialled out, self-control remained statistically significant for nearly every variable of health, wealth and public safety. Additionally, self-control was measured among 509 same gender dizygotic siblings, and siblings with lower levels of self-control were significantly more likely to 
smoke at age 12, have lower academic achievement, and participate in anti-social behavior even after controlling for IQ differences between siblings. Research findings suggest that successful emotion regulation is critical to healthy and adaptive functioning and has the potential to significantly influence an individual's well-being and overall quality of life.

The proposed study used a conceptual approach to examine the role of emotion regulation in caregivers of young children referred to parent-training. The purpose of the study was two-fold: (1) to determine whether caregivers referred to parent-training experience particular difficulties with emotion regulation, and (2) to understand the degree to which these difficulties correlate with levels of negative interactions, parental stress, children's behavior problems and children's emotion regulation at the beginning of treatment. Thus, the following review summarizes the emotion regulation literature by defining the construct, as well as describing the complex relationship between a parent's and a child's emotion regulatory abilities. Finally, emotion regulation is reviewed in the context of a variety of psychological disorders and maladaptive behaviors before concluding with a justification for the use of the current sample and research method.

\section{Emotion Regulation: A Definition}

Although a variety of definitions of emotion regulation exist within the literature, emotion regulation can be broadly conceptualized as, "the processes by which individuals influence which emotions they have, when they have them, and how they experience and express these emotions" (Gross, 1998, p. 275). Gross and Muñoz (1995) further defined emotion regulation as comprising two related processes -"the regulation (of something) by emotions, or the regulation of emotions themselves" (Gross \& Muñoz, 1995, p.152). Specifically, emotion regulation has been conceptualized as a, " multi-dimensional construct... involving the: (a) 
awareness, understanding, and acceptance of emotions; (b) ability to engage in goal-directed behaviors, and inhibit impulsive behaviors, when experiencing negative emotion; (c) flexible use of situationally-appropriate strategies to modulate the intensity and/or duration of emotional responses... and (d) willingness to experience negative emotions as part of pursuing meaningful activities in life" (Gratz \& Tull, in press, p. 6-7).

Yet, this overarching definition raises important questions in the field of emotion regulation. The process of emotion regulation can be conceptualized as including both internal and external influences. For example, individuals internally regulate emotion by using cognitive strategies to modify their experience of and reaction to emotions. External stimuli (ie., social support) can also impact the ability to regulate emotion by influencing an individual's experience and interpretation of emotion (Thompson, 1994). Both internal and external influences will be discussed in greater detail in the following sections.

Internal influences. A debate subsumed under the internal influences of emotion regulation literature concerns whether emotion regulation is truly focused on an individual's ability to control negative emotions or an individual's ability to control his or her behavior during a negative emotional experience (Gratz \& Tull, in press). Although some may equate emotional control with the ability to reduce or eliminate the experience of negative emotion (Kopp, 1989), others have argued for the importance of healthy regulatory abilities when one is experiencing negative emotion (Gratz \& Tull, in press). Internal strategies such as suppression and avoidance may be used to control negative emotion (Gross, 1998; Gross \& Levenson, 1997); however, such strategies may not only fail to relieve negative emotion (Gross \& Levenson, 1997) but they may actually intensify negative emotions by reinforcing maladaptive coping patterns 
(Gratz \& Tull, in press). Given such evidence, the argument that emotion regulation should be purely focused on emotional control does not appear to be sufficient.

Others have defended the approach that emotion regulation refers to the ability to control one's behavior while experiencing particularly negative emotions (Melnick \& Hinshaw, 2000). This functional perspective separates emotional control from behavioral control and suggests that by controlling the intensity of emotion, we can fulfill our true aim of controlling maladaptive behavior (Cole, Michel, \& Teti, 1994).

Although a universal definition of emotion regulation continues to evolve, there is no doubt that emotion regulation includes the ability to influence emotional experience, arousal, and expression (Gross \& Muñoz, 1995; Shields \& Cicchetti, 1998). Such regulatory abilities can be either conscious or unconscious (Gross, 1999) and automatic or intentional (Mauss, Cook, \& Gross, 2007). As we adapt to situations, we constantly use our emotions as cues to motivate our actions and fulfill our goals (Eisenberg, Hofer \& Vaughan, 2007; Eisenberg \& Morris, 2002; Thompson, 1994).

Emotion regulation is not a single process but rather a continuous cycle of emotional input and responses over time (Gross \& Muñoz, 1995). Gross and Muñoz (1995) conceptualized the process of emotion regulation as either antecedent-focused or response-focused. Antecedentfocused emotion regulation emphasizes actions before an emotion begins that affect its occurrence. Certain environments are much more likely to bring about positive emotions (e.g., a child's birthday party) compared to other environments which are much more likely to bring about negative emotions (e.g., a divorce courtroom). Therefore, the environment may prematurely increase the likelihood of some emotions occurring over others. Response-focused emotion regulation, however, is focused on the process of emotion regulation after the emotion 
has occurred. In this type of regulation, the individual experiences the emotion and then controls his or her expression of such emotions (Gross \& Muñoz, 1995).

External influences. In addition to a variety of internal processes that individuals may perform to regulate their emotions, researchers have also suggested that extrinsic factors play a vital role in an individual's emotion regulation abilities (Thompson, 1994). For example, social support, empathy and generosity from friends and family during an emotionally difficulty situation may play a powerful role in an individual's ability to control and adapt his or her emotions. Another extrinsic factor that may assist individuals in controlling their emotional responses is belief in a higher power. Religious beliefs and religious practices may aid individuals in regulating emotion by providing meaning to otherwise confusing and emotionally disruptive circumstances (Watts, 2006). Religious beliefs enable individuals to attribute the cause of negative events to an external higher power and cope with otherwise emotionally difficult events.

\section{Emotion Dysregulation: A Definition}

In contrast to emotion regulation, which is currently marked by an overabundance of definitions, far fewer definitions exist for the opposite construct of emotion dysregulation (Cole, Michel, \& Teti, 1994). Broadly, the idea can be conceptualized as a deficit in an individual's ability to control his or her emotional reaction especially within the context of a stressful situation (Carrère \& Bowie, 2012). Dysregulation occurs when emotions are over or underregulated implying that an individual has failed to achieve an adaptive and developmentally appropriate balance of emotional expression within the context of a given situation (Cicchetti, Ganiban, \& Barnett, 1991; Cole, Michel, \& Teti, 1994). 
Emotion dysregulation can occur in the context of both negative and positive emotion. Gross and Thompson (2007) add that emotions become dysfunctional when they are of the wrong type, when they occur at the wrong time, or when they are displayed at the wrong intensity level. Therefore, emotionally dysregulated individuals are unable to properly meet typical and expected emotional development goals and may exhibit poor control over their emotional expression (Cole, Michel, \& Teti, 1994; Kopp, 1989).

Although the development of emotion regulation has been conceptualized as occurring primarily in childhood (Cole, Michel, \& Teti, 1994), the process not only continues into but remains a necessary part of an individual's social and emotional functioning throughout adulthood. As adults, individuals are expected to understand and follow the social and culturallybased rules that direct the experience and appropriate expression of emotions in a variety of personal and professional contexts (Gross \& Munoz, 1995). If such rules are not met, emotion dysregulation in adulthood can have serious implications upon an individual's well-being and productivity as well as his or her social and emotional health.

Despite an understanding emotion dysregulation in a variety of psychological conditions and its implications upon health and well-being, research exclusively focusing on the construct has only begun to emerge within the past decade (see Gross \& Thompson, 2007).

\section{The Difficulties in Emotion Regulation Scale}

Prior to 2001, no measures of adolescent/adult emotion regulation existed (Garnefski \& Kraaij, 2007). Developed in 2004, The Difficulties in Emotion Regulation Scale (DERS; Gratz \& Roemer, 2004) has been used with a variety of populations that have commonly experienced psychological difficulty with emotion regulation including Anorexia Nervosa (Harrison, Sullivan, Tchanturia, \& Treasure, 2009), Generalized Anxiety Disorder (Roemer, et al., 2009), 
Post- Traumatic Stress Disorder (Bonn-Miller, Vujanovic, Boden, \& Gross, 2011) and Borderline Personality Disorder (Gratz, Lacroce, \& Gunderon, 2006). The DERS has also been significantly associated with individuals engaging in a variety of emotion-regulating behaviors such as alcohol abuse (Fox, Hong, \& Sinha, 2008), nonsuicidal self-injury (Perez, Venta, Garnaat, \& Sharp, 2012), cocaine-seeking patients (Fox, Axelrod, Paliwal, Sleeper, \& Sinha, 2007) and self- harm (Labouliere, 2009). A variety of populations have also been explored including re-victimized female inmates (Walsh, DiLillo, \& Scalora, 2011), marijuana users (Bonn-Miller, Vujanovic, Boden, \& Gross, 2011), a community sample of adolescents (Neumann, van Lier, Gratz, \& Koot, 2010), trauma survivors (Ehring \& Quack, 2010) and maltreated youth (Vettese, Dyer, Li, \& Wekerle, 2011). The measure's impressive psychometric properties and use with a variety of populations is indicative of its strength as a measure of adult emotion dysregulation.

\section{Transmission of Emotion Regulation between Parents and Children}

Because emotion regulation is a developmental process that begins in early childhood, it is important to understand familial factors involved in the transmission of emotion regulation from parents to children. Research suggests that emotion regulation may be an inherited trait and thus children of dysregulated parents may be predisposed toward difficulties in their ability to moderate negative affect (Ben-Porath, 2010) Additionally, recent findings in developmental neuroscience indicate that areas in the prefrontal cortex seem to play a significant role in cognitive and attention-related processes that contribute to emotion regulation particularly throughout early and middle childhood (Calkins \& Howse, 2004). The anterior cingulate cortex also includes an area related to emotional processes, limbic and endocrine systems. The physiological processes that govern these biological systems interact with a child's behavioral 
strategies to influence his or her ability to successfully regulate emotion (Calkins \& Howse, 2004).

Temperament is another biologically-based process that remains relatively consistent across time and influences a parent's and child's ability to understand and express emotion and (Schmitz, Fulker, Plomin, Zahn-Waxler, \& DeFries, 1999). Some aspects of temperament have been shown to have a degree of genetic heritability (Zawadzki, Strelau, Oniszcenko, Riemann, \& Angleitner, 2001). An individual's temperamental disposition sets the stage for interpretation and response to emotions (Marziali, Damianakis, \& Trocmé, 2003). Although environmental influences have been shown to shape each child's temperament differently (Davidson, 1999), emotionally dysregulated caregivers and their children are likely to experience similar temperamental difficulties (Marziali, Damianakis, \& Trocmé, 2003) in addition to difficulties with emotion regulation (Carrère \& Bowie, 2012).

Despite the clear influence of biology on emotion regulation, animal research has shown the overwhelming influence of the caregiver environment above and beyond inherited traits (Davidson, Fox, \& Kalin, 2006). Many studies examining the relation between attachment and emotion regulation have been conducted and provide evidence for the role of attachment in the development and functioning of physiological processes found to be related to emotion regulation (Davidson, Fox \& Kalin, 2006). The majority of these studies employ the strange situation paradigm to illustrate differences between securely and insecurely attached children's expectations of their caregivers' ability to help them regulate emotion (Calkins \& Hill, 2006). In fact, when children are young, they almost exclusively rely on adults to help them manage and control their emotions (Morris, Silk, Steinberg, Myers, \& Robinson, 2007). Parents play a significant role in choosing and shaping a child's environment such that a child has a greater 
chance of experiencing a range of emotions (Thompson, 1991). When children are exposed to a variety of emotions and affective environments, they become aware of a range of possible emotions and forms of emotional expression thereby expanding their repertoire of emotional knowledge (Morris et al., 2007). Parents also model emotional control and appropriate behavioral responses to stressful situations. Children, in turn, internalize such strategies and replicate the behavior they observe (Morris, et al., 2007). Additionally, parents use positive reinforcement and punishment techniques to help children understand and control their emotions. For example, a parent who diverts a frustrated child's attention away from an unproductive task implicitly teaches the child to self-initiate redirection in future frustrating situations (Thompson \& Meyer, 2006). Children can then use these strategies to independently regulate their experience of negative emotions during emotionally challenging circumstances (Bloch, Moran \& Kring, 2009; Macklem, 2008).

Parents who practice a positive parenting style, including on-going expressions of warmth and the ability to recognize and appropriately respond to a child's distress cues, have children who are better able to regulate their emotions (Davidov \& Grusec, 2006). When parents' emotions are focused on the best interest of their children, such emotions contribute to sensitive and responsive parenting as well as effective parenting environments (Dix, 1991). Thus, when a child's environment is characterized by feelings of positivity and predictability, children learn to think flexibly and use problem solving skills to appropriately resolve difficulties and manage intense emotion (Macklem, 2008).

Parents also teach emotion regulation skills through reciprocal interactions with their children. Through such interactions, parents are able to reinforce and model appropriate emotion regulation strategies and cultivate a parent-child relationship characterized by collaboration and 
cooperation (Macklem, 2008). Eisenberg et al., (1999) noted that when parents coach children's emotional expression, children learn to inhibit negative affect and soothe themselves as well as improve their attention span to a single task.

Adaptive emotion regulation skills not only impact the parent-child relationship but have been found to help children develop positive social skills such as the ability to successfully navigate social interactions and increase their social and emotional competence (Denham et al., 1997). Davidov and Grusec (2006) found that mothers who were responsive to their child's distress had children who responded empathetically to others. However, when parenting styles are characterized as negative, cold, angry and unresponsive or disengaged from children's needs and emotions, children have difficulty controlling and regulating their emotions. For example, a parent who screams at bickering siblings to stop fighting and walks away has not shown the children useful techniques to manage their emotions in future situations (Calkins \& Hill, 2006). When parents model emotional dysregulation, parents demonstrate ineffective coping skills which place a strain on children's development and the quality of the parent-child relationship (Dix, 1991). Such children have also been shown to lack a basic understanding of emotions, which in turn, may impact a child's ability to effectively relate to and interact with others (Denham, Zoller \& Couchoud, 1994; Denham et al., 1997). In contrast to emotional control, inappropriate displays of negative emotions cultivate children's inattention, poor problem solving abilities and undermine collaborative parent-child interactions (Dix, 1991).

Certainly the transmission of emotion regulation between a parent and child is a bidirectional, interactive process. A child's temperament and personality characteristics influence a parent's emotional response to a child. Thus, the child plays an important role in this dyadic relationship and the development of his or her own emotion regulation (Calkins et al., 1998). 


\section{Similarity between parents' and children's emotion regulation styles.}

Given the transmission of emotion regulation abilities between caregivers and children, it is not surprising that parents and children experience common difficulties regarding emotion regulation (Ben-Porath, 2010; Carrère \& Bowie, 2012). However, research has found that differences between maternal and paternal contributions to their child's development of emotion regulation exist (Cassano, Perry-Parrish, \& Zeman, 2007). This may be a result of the fact that mothers are more likely to play an active role in their child's emotional development than fathers (McDowell, Kim, O’Neil, \& Parke, 2002). Bariola, Hughes and Gullone (2012) found support for mothers' use of emotional suppression strategies according to the Emotion Regulation Questionnaire (ERQ) (Gross \& John, 2003) (e.g., "When I am happy, I am careful not to show it") and child use of suppression strategies. No support was found for use of emotional reappraisal strategies (e.g., "I control my feelings about things by changing the way I think about them") between children and mothers or fathers, however the authors discussed the idea that reappraisal is an internal, cognitive construct and may not be actively modeled (Bariola, Hughes \& Gullone, 2012).

In a five-year longitudinal study of multiracial families with children between the ages of seven and nine years of age, Carrère and Bowie (2012) examined the relation between parents' emotional dysregulation (as evidenced by subclinical levels of depression and hostile behavior) with teachers' reports of their children's emotion regulation (as evidenced by the children's internalizing and externalizing behavior). Results indicated that fathers' dysregulated display of hostility was significantly associated with their children's externalizing behavior in the school setting indicating a strong similarity between the emotion regulation difficulties of fathers and their children. 
Parents and children also seem to share positive emotion regulation abilities. Cole, Teti and Zahn-Waxler (2003) found that preschool children reciprocated their mother's positive responses with their own display of pro-social emotions. This finding indicates that children who are exposed to parental models of positive emotion regulation are able to recognize and appropriately respond to others' emotional cues. Similarly, mothers who displayed sympathetic responses to a needy individual had girls who also indicated strong feelings of sympathy and displayed less negative affect (Fabes, Eisenberg, \& Miller, 1990) further supporting the notion that children are likely to exhibit similar forms of prosocial emotion regulation strategies as their parents.

\section{Emotion Regulation and Psychological Disorders}

It is well known that a strong link exists between the intergenerational transmission of parent and child psychopathology. As early as infancy, children of more anxious parents have shown more fearful responses upon interactions with a stranger as compared to children of nonanxious parents (Murray et al., 2008). As children age, interaction styles between anxious parents and their children may also contribute to the transmission of anxiety (Whaley, Pinto \& Sigman, 1999). Children of depressed parents are also at risk for a wide range of psychological difficulties, including but not limited to risk of clinical depression (Downey \& Coyne, 1990). Such children may experience issues such as social and academic consequences that have been found to be similar to those of children of parents with more severe psychopathology (Downey \& Coyne, 1990). Given the established transmission of psychopathological disorders between parents and children, it is also likely that parental psychopathology may contribute to the transmission of maladaptive emotion regulation strategies between parents and children. 
The failure to appropriately regulate emotion has been implicated in the context of many psychological conditions and maladaptive behaviors across diverse populations (see Gratz \& Tull, in press for a review). Emotion regulation is not only an important but critical aspect of mental health (Gross \& Levenson, 1997; Watkins \& Brown, 2002). According to a review by Gross and Levenson (1997), over half of the Axis I and all of the Axis II disorders include core elements of emotion dysregulation. Cole, Michel and Teti (1994) describe a variety of emotion regulatory difficulties that may apply to multiple psychological disorders: "inappropriateness of affect, chronic worry or tension, blunting or avoidance of emotions, constriction of affect, unpredictable fluctuation between emotionlessness and rage, elation, or dejection, the predominance of one emotion and the relative absence of another, and sustained negative emotions are common examples of emotion characteristics associated with clinical disorders" (Cole, Michel \& Teti, 1994, p. 77). Taken together, this indicates that individuals with mental health disorders make have core difficulties with emotion regulation.

In particular, individuals with Major Depressive Disorder (MDD) are known to have difficulty controlling feelings of sadness or hopelessness. They may consistently use maladaptive and ineffective strategies such as rumination, avoidance and social withdrawal in attempts to regulate unwelcome emotion instead of selecting from a flexible repertoire of appropriate and adaptive emotion regulation strategies based on the demands of the presenting situation (Campbell-Sills \& Barlow, 2006). Such cognitive deficits may help explain the link between emotion regulation difficulties and the maladaptive responses that characterize individuals with depression (Joormann \& D'Avanzato, 2010). Even subclinical amounts of depressive symptoms can be understood as a form of emotion dysregulation in adults because those experiencing such symptoms have difficulty self-soothing and moderating their emotions (Carrère \& Bowie, 2012). 
Given the inherent connections between emotion regulation and psychopathology, it is not surprising that people with depression have also been found to exhibit a range of emotion regulation difficulties. In particular, individuals with depression have difficulty controlling and diminishing negative emotional states (Brockmeyer et al., 2012). Given the well-established similarity between parents' and children's emotion regulation styles, it follows that caregiving environments characterized by low levels of positive emotion, low levels of sadness regulation, and moderate to high levels of psychological control have been found to predict higher levels of depressive symptoms in preadolescent girls (Feng et al., 2009). In one study, mothers with depression and their 8-13 year old children reported responding to sadness-eliciting stories using fewer and lower quality emotion regulation strategies as compared to non-depressed mothers and children (Garber, Braafladt, \& Zeman, 1991). In another longitudinal study of parental hostility and adolescent functioning, Reeb, Conger and $\mathrm{Wu}$ (2010) found that fathers experiencing depression and displaying expressions of hostility were more likely to have daughters with depressive symptoms. These studies demonstrate the link between parental emotional dysregulation and childhood emotional difficulties (Reeb, Conger, \& Wu, 2010).

\section{Stress and Emotion Regulation}

Chronic stress has been found to exacerbate the emergence of preexisting individual vulnerabilities that contribute to the onset of emotion dysregulation and resulting psychopathology. Despite the particular form of psychopathology, a disruption in emotion regulatory processes can be implicated in each. In some cases, an individual may attempt to cope with his or her emotional dysregulation by engaging in behaviors that may immediately function to relieve emotional stress but actually perpetuate psychological difficulties long term. Behaviors such as intentional self-harm (Gratz \& Roemer, 2008), binge eating (Leahey, Crowther \& Irwin, 
2008) and substance use (Fox, Hong \& Sinha, 2008) have all been linked to emotion regulation difficulties (Gratz \& Tull, in press). Together, this information indicates that ongoing stress negatively impacts an individual's ability to control and appropriately express his or her emotions.

Although originally conceptualized as an adaptive response to immediate threat, stress can also inspire or exacerbate an individual's preexisting vulnerabilities and various forms of psychopathology. The prolonged mobilization of the stress response thus becomes

physiologically and psychologically pathogenic (Blackburn-Munro \& Blackburn-Munro, 2001). When the stress response is consistently activated, the result is chronic life stress. This response has been linked to the development and exacerbation of a variety of medical conditions as well as psychological disorders including Post-Traumatic Stress Disorder, Schizophrenia, a variety of anxiety disorders, and Major Depressive Disorder (Coyne \& Downey, 1991; Cullenberg, 2003; Hammen, 2005; Uliaszek, et al., 2012). A plethora of studies conducted within the past couple of decades has examined the effect of stress upon depression (Kessler, 1997; Mazure, 2006;

Muscatell, Slavich, Monroe, \& Gotlib, 2009). While some have focused on the short-term effects of a recent, stressful life event and depression (Aseltine \& Kessler, 1993; Umberson et al., 1992), others have focused on its long-term consequences (Kessler \& Magee, 1994).

\section{Emotion Regulation and Parenting Stress}

Parents of children with behavior problems are likely to experience a range of negative emotions in reaction to the children's difficult behavior (Ben-Porath, 2010). Such emotions may include shame, sadness, anxiety and anger, (Cameron, Snowdon \& Orr, 1992; Carpenter \& Halberstadt, 2000), all of which may contribute to parents' heightened stress levels. Parents who experience high levels of parenting stress may also have difficulty regulating their emotions. 
Parenting stress has been defined as, "a set of processes that lead to aversive psychological and physiological reactions arising from attempts to adapt to the demands of parenthood" (DeaterDeckard, 2004, p. 6). Parenting stress occurs when anticipated parenting demands exceed a parent's available resources to fulfill such demands (Deater-Deckard, 2004). Sources of parenting stress vary widely across parents depending upon the parent's individual perception and cognitive appraisal of the experience as negative (Deater-Deckard, 2004). Such experiences may include elements of emotional pain and anxiety as well as a perceived lack of control or ability to fulfill ones perceived parenting expectations (Deater-Deckard, 2004). Further, evidence suggests that parents have varying tolerance levels for childhood misbehavior, which in turn may impact a parent's likelihood of feeling additional stress as a result of a child's given behavior (Brestan, Eyberg, Algina, Johnson, \& Boggs, 2003). Although life stressors outside of the parenting role are likely to impact parenting stress, parenting stress has been specifically found to moderate the relationship between parenting behavior and child outcomes (Creasey \& Reese, 1996; Deater-Deckard, 2004).

Two major conceptualizations dominate the parenting stress literature in an attempt to explain the causes and effects of parenting stress. The most extensively understood theory, called the parent-child-relationship stress theory (P-C-R theory) divides parenting stress as arising from separate but interacting domains: parent-driven variables (i.e., parental psychopathology), childdriven variables (i.e., child behavior problems) and parent-child relationship variables (i.e., conflict) (Crnic \& Greenberg, 1990; Deater-Deckard, 2004). Each of these variables, while independent, significantly influences each other. For example, a parent experiencing depression may emotionally withdraw from their child, thereby influencing the child's defiant and aggressive behavior which in turn causes the parent to feel increasingly stressed (Deater- 
Deckard, 2004). The second theory of parenting stress, appropriately called the daily hassles theory, suggests that parenting stress results from the accumulation of minor parenting struggles that most parents face on a regular basis (Deater-Deckard, 2004).

Although each of these theories conceptualizes parenting stress differently, a parent's ability to successfully utilize coping mechanisms in response to the various demands of parenthood remains central to a parent's level of parenting stress (Deater-Deckard, 2004). Therefore, an adult's inability to effectively react and adapt to parenting difficulties causes parenting stress. External coping mechanisms, such as social support, may also impact an individual's ability to regulate his or her emotions in response to parenting stress (DeaterDeckard, 2004). In a ten-year longitudinal study of disabled children, mothers who utilized access to effective social support did not experience increased parental distress, indicating the power of external social support in emotion regulation (Hauser-Cram, Warfield, Shonkoff, \& Krauss, 2001). Parents of children with multiple behavior problems have been found to experience high levels of parental stress across all domains on the Parental Stress Index (PSI; Abidin, 1990; De Bruyne, et al., 2009) and may engage in coercive, overly harsh as well as other ineffective parenting practices (Forgatch \& Patterson, 2003) which may further exacerbate child behavior problems (Jaffee, Caspi, Moffitt, \& Taylor, 2004). Thus, it follows that parents referred for parent-training may experience high levels of parental stress. In a sample of parents of children with cognitive and developmental delays, Baker, Blacher, Crnic, and Edelbrock (2002) found that child behavior problems contributed to parental stress over and above the child's cognitive delay indicating the impact of children's behavior problems on parental stress levels.

Parenting stress influences the overall affective environment as well as the quality of the parent-child interactions (Deater-Deckard, 2004). Although capturing the particular causal 
mechanism behind this relationship is difficult to measure and explain, current theories posit multiple valid conceptualizations. Joinson, Heron, von Gontard, Butler, Golding, and Emond (2008) suggest that stressed parents may have difficulty responding to children with sensitivity. In turn, children's stress levels may increase, and they may react to stressful interactions with parents by engaging in negative behavior (Morison, 1998). Finally, parents who are struggling to cope with stress may also have difficulties with emotion regulation (Deater-Deckard, 2004).

Subsequent research has further investigated the particular ways in which parental stress may contribute to children's emotional expression. Fabes, Leonard, Kupanoff and Martin (2001) had parents (51 mothers and 6 fathers) fill out self-report questionnaires regarding their reactions to their preschool-aged children's negative emotions. The authors found that parental distress moderated the relationship between parents' harsh coping strategies in response to their children's negative emotions and the intensity of children's emotional responses. Overall, the children demonstrated fewer negative emotions when parents' exhibited harsh coping and high levels of parental distress. However, when these children exhibited negative emotions, such displays were often intense, marked by emotional dysregulation and affected their ability to behave and react appropriately in social situations (Fabes, Leonard, Kupanoff \& Martin, 2001). Taken together, this evidence demonstrates that parental stress and emotional dysregulation have negative consequences upon the overall caregiving environment, children's behavior, and the transmission of dysfunctional emotion regulatory strategies between parent and child.

\section{Emotion Regulation and Negative Interactions with Others}

Emotionally dysregulated individuals may also engage in hostile and/or negative interactions with others. Angry or hostile behaviors represent a powerful, affective state that signals emotional dissatisfaction and may communicate a response to an immediate or 
impending threat (Garside \& Klimes-Dougan, 2002). Individuals with a propensity toward hostile behavior may be more likely to assess a given situation as anger provoking and react in emotionally intense ways. This behavioral pattern may indicate difficulty with emotion regulation because these individuals have trouble remaining calm in stressful circumstances (Carrère \& Bowie, 2012; Sloan et al., 2001). Hostility may also negatively affect an individual's ability to physiologically self-soothe. Sloan et al. (2001) exposed 30 participants, representing a range of hostility levels, to a variety of psychological and physiological stressors and found that the presence of hostility negatively influenced participants' abilities to reduce their physiological arousal following a stressful experience. Thus, the presence of anger and hostility has been found to contribute to emotionally intense reactions in adults particularly under stressful circumstances (Barnett, Fagan, \& Booker, 1991; Carpenter \& Halberstadt, 2000).

When parents frequently display hostile or angry emotions in the presence of their children, children internalize and replicate such dysregulated emotional strategies in subsequent social situations (Chang, Schwartz, Dodge, \& McBride-Chang, 2003; Suveg, Jacob, \& Payne, 2010). Such emotions comprise a larger cluster of reactions that may be indicative of harsh parenting. Harsh parents may also exhibit behaviors such as yelling, negative commands, and obvious expressions of anger as well as physical threats and aggression (Chang et al., 2003). Such negatively laden emotional reactions contribute to a negative affective environment which may also affect the quality of parent-child interactions as well as the child's social interactions. In one study, preschool children's angry and frustrated emotional reactions were found to match parents' negative emotions (Eisenberg \& Fabes, 1994). Further research has demonstrated strong correlations between parents' and children's negative emotions when the dyads are engaged in constructive play activities (Melnick \& Hinshaw, 2000). Research has also explored children's 
physiological reactions to stressful parent-child interactions (Gottman \& Katz, 2002) as well as inter-parental aggression (Davies, Sturge-Apple, Cicchetti, Manning, \& Zale, 2009). Results revealed that children's increased cortisol levels were associated with instances of inter-parental aggression, and rapid heart rate increases were associated with stressful parent-child interactions. In particular, mothers' display of negative behavior has been related to poor physiological regulation in children (Calkins, Smith, Gill, \& Johnson, 1998). Thus, an intense, emotionally negative climate not only impacts a child's ability to regulate his or her emotions but also has negative physiological implications upon the child's well-being.

In contrast to a hostile parenting style, parents who demonstrate awareness of their own as well as their children's emotions are better able (a) to help their children differentiate between emotions; (b) answer children's questions about emotions, and (c) to help children recognize emotions within their play (Katz \& Windecker-Nelson, 2004). Children of emotionally-aware parents showed more positive peer interactions than children of mothers who demonstrated less awareness of their emotions (Katz \& Windecker-Nelson, 2004). Such children also had fewer occurrences of negative conversation, negative affect and breakdowns while playing with peers. Taken together, this information suggests that when parents are aware of and able to control their emotions, they are likely to create a positive emotional climate marked by emotional understanding and acceptance.

\section{Children's Behavior Problems and Parental Emotion Regulation}

Researchers consider the relationship between parent emotion regulation and child emotion regulation to be bi-directional. A child who exhibits oppositional, defiant and aggressive behavior may place additional strain on a parent's ability to regulate his or her emotions (De Bruyne, et al., 2009), which may lead to overreactive discipline strategies following child 
misbehavior (Lorber \& O’Leary, 2005). The perspective that emotionally dysregulated parents contribute to or even perpetuate their children's negative behavior has also been explored. In a study assessing maternal interactive styles during three mother-child tasks, Calkins, Smith, Gill, and Johnson (1998) found that negative maternal behavior was related to child noncompliant behavior.

Emotion regulation difficulties are an inherent piece of child behavior disorders, the most common diagnostic category for clinically referred children (Keenan \& Wakschlag, 2004). According to the DSM diagnostic manual, difficulty controlling and expressing emotion remains central to many child behavior diagnoses [DSM-IV-TR (2000) 4th ed., text rev.]. For example, children with Oppositional Defiant Disorder (ODD) and Conduct Disorder (CD) frequently display a pattern of hostile, negativistic, and even aggressive behavior [DSM-IV-TR (2000) 4th ed., text rev]. Children with ADHD frequently have difficulty managing frustration levels, and as a result, may suffer in academic or social domains (Barkley, 1998).

Parental emotion dysregulation has also been implicated in a variety of child behavior problems including later romantic relationship conflict (Kim, Pears, Capaldi \& Owen, 2009), disordered eating behaviors (Buckholdt, Parra, \& Jobe-Shields, 2010) and child maltreatment (Shields \& Cicchetti, 1998). Webster-Stratton and Eyberg (1982) found a significant relationship between child temperament and child behavior problems indicating that parents of children with naturally difficult temperaments may be more likely to have children with behavior difficulties. Mamorstein and Iacono (2004) demonstrated a significant association between children diagnosed with $\mathrm{CD}$ and fathers' antisocial behavior, indicating a link between fathers' emotion dysregulation and their children's emotion dysregulation. In addition, parents of children diagnosed with conduct problems have been found to demonstrate less awareness and 
understanding of their own emotions (Katz \& Windecker-Nelson, 2004). They also dedicate less time and thought to helping their children cope with and control their emotions, and coach their children's negative emotions less often than mothers of control children (Katz \& WindeckerNelson, 2004). Children with ODD and CD commonly display oppositional, defiant and aggressive behavior that is likely to arouse and challenge parents' emotional control (DeaterDeckard, 2003). As a result, negative parenting behavior such as yelling, negative talk and physical aggression are more likely to occur during interactions with a child who has a disruptive behavior disorder (Mammen, Kolko, \& Pilkonis, 2003).

Maltreating caregivers exhibit a range of emotionally and behaviorally maladaptive qualities indicating emotional dysregulation (Howes, Cicchetti, Toth, \& Rogosch, 2000; Marziali, Damianakis, \& Trocmé, 2003). Marziali, Damianakis, and Trocmé (2003) conceptualized emotion dysregulation as a core element of maltreating caregivers' problematic psychosocial behaviors. Maltreating caregivers commonly mis-code and inappropriately react to others' emotions as a result of their faulty cognitive interpretation of their own and others' emotions (Marziali, Damianakis, \& Trocmé, 2003). Maltreating caregivers may therefore incorrectly appraise the meaning and function of their children's emotions resulting in overreative, and potentially punitive, or underreactive (e.g., ignoring the situation) emotional reactions (Marziali, Damianakis, \& Trocmé, 2003). Shipman and Zeman (2001) compared 25 maltreating mothers to a control group of 25 non-maltreating mothers of children between the ages of 6-12 years. Maltreating mothers reported less understanding of their children's emotions and used less effective strategies when attempting to help their children manage emotionally difficult situations. Such maladaptive parental socialization practices help determine a child's ability to express emotion and the degree of emotional arousal he or she may feel. These findings 
complement the later findings of Shipman et al. (2007) comparing emotion validation and invalidation of maltreating to non-maltreating mother-child dyads during a parent-child emotion interaction task. Maltreating mothers validated and guided their children's emotions less often than non-maltreating mothers. Subsequently, children of maltreating caregivers demonstrated greater emotion dysregulation and fewer emotional coping strategies (Shipman, Schneider, Fitzgerald, Sims, Swisher \& Edwards, 2007; Shipman \& Zeman, 2001). Together, these findings provide background for the behavior problems commonly exhibited by children of maltreating parents and parental emotion regulation.

Given emotionally dysregulated parents' difficulty in controlling their emotional response and assisting their children in regulating emotional arousal, such parent-child dyads may become caught in a vicious cycle of increasingly negative exchanges (Dishion, French, \& Patterson, 1995; Eddy, Leve, \& Fagot, 2001). Behavior such as scolding, arguing, yelling and temper tantrums, characteristic of emotion dysregulation, may perpetuate such vicious cycles (Dishion, French, \& Patterson, 1995; Eddy, Leve, \& Fagot, 2001). Occasionally, such negative interactions may escalate to physical aggression. Patterns such as this are maintained by a cycle of negative reinforcement whereby family members attempt to avoid or remove the aversive behavior of another (Dishion, French, \& Patterson, 1995; Eddy, Leve, \& Fagot, 2001). Negative or aggressive behavior (i.e. yelling at children to stop hitting each other) is reinforced when such behavior successfully controls or limits another's behavior. The individual thus learns to be increasingly coercive in order to achieve the desired outcome and the cycle of dysregulated emotions is perpetuated. Such coercive patterns of interaction between parents and children with behavior disorders may model negative language and behavior that children learn and are likely to repeat. 


\section{Purpose of the Present Study}

It is well known that clinically referred children present with high rates of disruptive behavior disorders (Keenan \& Wakschlag, 2004). In addition, the parents of such children are likely to experience high levels of parenting stress (De Bruyne et al., 2009) and may engage in extreme verbal and physical discipline practices (Dishion, French, \& Patterson, 1995), behavior which may be indicative of emotion dysregulation (Mammen, Kolko \& Pilkonis, 2003). Given the likelihood that parents and children referred to a parent-training program will have experienced difficulties with emotion regulation, surprisingly little is known about the role of emotion dysregulation in caregivers of children referred to parent-training programs. Some researchers have begun to speculate a theoretical benefit for incorporating aspects of emotion regulation based treatments, like Dialectical Behavior Therapy (DBT; Linehan, 1998), into parent-training (Ben-Porath, 2010). To date, however studies of emotion regulation have largely focused on typically developing children and explored the variables associated with the development of adaptive or maladaptive emotion regulatory processes in addition to the transmission of such processes between parents and children. Literature discussing the integral role of emotion regulation in caregivers referred to parent training is currently lacking.

Using a conceptual approach, the present study was the first of its kind to explore the role of caregiver emotion regulation in parent training during the pretreatment assessment. The caregivers in this study were referred to a parent-training program for difficulties managing their child's misbehavior. Thus, the first purpose of this study was to understand whether caregivers who are referred for parent training have difficulty with emotion regulation. A second purpose of this study was to explore caregiver and child variables that may predict caregiver emotion dysregulation. Thus, a goal of the current study was to account for the variance in caregivers' 
emotion dysregulation by correlating variables previously found in research to be related to parent and child emotion with an empirically validated measure of caregiver emotion dysregulation. Parenting variables included caregiver hostile/ negative interactions with the child and level of parenting stress. Child variables included child emotion regulation and externalizing behavior. The final purpose of this study was to determine the relation between caregiver emotion regulation and child emotion regulation according to caregiver report.

The aim of the current study was multi-fold: to better understand the difficulties caregivers referred to parent-training may experience prior to the commencement of parent training and to broaden our understanding of the construct of emotion regulation in caregivers. This knowledge may be used clinically to inform the pretreatment assessment, to provide evidence for the importance of including a measure of change in parental emotion regulation from pretreatment to post-treatment in parent-training outcome studies, and to determine the appropriateness of including emotion regulation treatment components in parent-training programs. An overarching goal of the study was to create a greater focus and awareness of the potential for parent training to influence parents' emotion regulation skills.

\section{Justification of Sample}

The current sample was specifically chosen to examine emotion regulation in a clinical population of parents referred for parent training. Children with behavior problems are at an increased risk for experiencing emotion regulation difficulties. When parents of such children are referred for parent training, they are likely to be experiencing difficulties managing their children's disruptive behavior and negative emotions. Significant levels of parenting stress may accompany parents' difficulties regulating their own emotions. Children of such parents may also experience emotion regulation difficulties and subsequent behavior problems. By sampling 
the emotion regulation levels of parents referred for parent training in the pretreatment portion of a parent intervention context, this study was designed to capture the degree to which emotion dysregulation may be related to parental stress, child behavior problems and child emotion regulation abilities.

\section{Hypotheses}

\section{Research Question 1}

Are caregivers and children referred to parent-training more emotionally dysregulated than a typical sample of caregivers and children? Specifically, it was hypothesized that the current sample of caregivers would present with significantly higher levels of emotion dysregulation (i.e., high total scores on the DERS) than a typical sample of adults (Gratz \& Roemer, 2004). It was also expected that the current sample of children would present with significantly higher levels of emotion dysregulation, as indicated by higher total scores on the Emotion Regulation Checklist (ERC; Shields \& Cicchetti, 1997), than a typical sample of children (Blandon, Calkins, Keane \& O’Brien, 2008; Graziano, Reavis, Keane \& Calkins, 2007). Previous research supports the expectation that the caregivers of children with behavior problems (De Bruyne, et al., 2009; Lorber \& O’Leary, 2005) and the children themselves (Keenan \& Wakschlag, 2004; Rogosch, Cicchetti, \& Toth, 2004) may experience difficulties with emotion regulation.

\section{Research Question 2}

Is caregiver emotion regulation related to hostile and negative interactions with their child? Specifically, it was hypothesized that caregiver emotion regulation (i.e., high total scores on the DERS) would be positively correlated with the rate of negative talk in structured play situations with the child. Previous literature supports the notion that parents of children with 
behavior problems engage in negative parenting practices such as yelling, critical statements, and aggression (Mammen, Kolko \& Pilkonis, 2003).

\section{Research Question 3}

Is caregiver emotion regulation related to caregiver overall stress level? Specifically, it was hypothesized that high total scores on the DERS would be positively correlated with higher overall scores on the PSI as well as specifically on the Parenting Distress, Parent-Child Dysfunction and Difficult-Child subscales, indicating that emotionally dysregulated parents would have higher levels of overall parenting stress, more problematic relationships with their children and perceive their children to be more difficult. A wealth of existing literature indicates that a parents' ability to successfully cope with parenting stress is directly linked to his or her degree of overall stress (Deater-Deckard, 2004). Given that parents of children with behavior problems experience particularly high stress levels (De Bruyne et al., 2009), it was expected that emotion dysregulation would be positively related to parenting stress.

\section{Research Question 4}

Is caregiver emotion regulation related to child level of disruptive behavior problems? Given the previous literature relating caregiver emotion regulation difficulties to child behavior problems (Rogosch, Cicchetti, \& Toth, 2004), it was hypothesized that high total scores on the DERS would be negatively correlated with children's level of compliance, indicating that emotionally dysregulated parents would have children with lower levels of compliance in response to parental commands. It was also hypothesized that high total scores on the DERS would be positively correlated with high total scores on the Child Behavior Checklist (CBCL; Achenbach \& Rescorla, 2000; 2001) as well as high scores on the internalizing and externalizing subscales. Finally, it was also expected that high total scores on the DERS would be positively 
correlated with high ECBI intensity and problem scores, indicating that emotionally dysregulated parents would have children with high levels of behavior problems.

\section{Research Question 5}

Is caregiver emotion regulation related to children's emotion regulation according to parent report? Based on the literature that suggests that parents behaviorally and biologically transmit emotion regulation strategies and temperamental characteristics to children (Ben-Porath, 2010; Carrère \& Bowie, 2012; Marziali, Damianakis, \& Trocmé, 2003), it was hypothesized that emotion dysregulation in caregivers would be positively related to emotion dysregulation in children. For this research question, both caregiver and child emotion regulation were based on parent report.

\section{Method}

\section{Participants}

The sample was composed of 32 primary caregiver-child dyads referred for parent training. Some of the participants were recruited at the Quin Curtis Center at West Virginia University, a university-based mental health clinic. Graduate student therapists provided information about the study to caregivers of 2-9 year old children who had been referred to parent-training services and whose child presented with disruptive behavior. For interested families, graduate student therapists asked caregivers to provide permission to be contacted by research staff. Upon receipt of permission, research staff contacted caregivers to provide more information about the study, arrange a meeting to obtain informed consent, and begin data collection with consenting participants.

Community therapists from surrounding areas also assisted in participant recruitment. Community therapists informed recently-referred, eligible caregivers of 2-9 year old children 
about the project. Interested caregivers were then given the option to sign a permission to contact form. Once received, research staff contacted the family, inquired about study eligibility criteria and if eligible, scheduled a meeting to complete study measures. One community referred participant was already enrolled in the study entitled, "Short Term Treatment Outcomes in Community Mental Health Agencies" (IRB Approved: H-24075). Therefore, data collection and overlapping measures were shared between both studies for this participant. In all cases, data collection was led by the same researcher. In a few cases, another researcher was also present to assist.

All data were collected in either the participants' place of residence or at the Quin Curtis Center, depending upon caregiver preference. If multiple children from a family qualified for the study, only one child was chosen to participate. All participants, regardless of recruitment site did not have more than three parent-training sessions prior to the administration of study measures so as to ensure that participants received minimal treatment intervention. Additionally, children previously diagnosed with an Autism Spectrum Disorder, according to parent report, were excluded from the current study as a result of inherent difficulty with emotion regulation. The pretreatment assessment was identical across all participants.

Demographic data on caregiver age, caregiver marital status, caregiver education level, caregiver sex, caregiver race, family income as well as child age, sex and race were analyzed for the 32 participants in the investigation. Table 1 displays the means and standard deviations for caregiver age, child age and family income. Three caregivers did not report their family income and thus this statistic was based off of $\mathrm{N}=29$ families. Table 2 displays the means and standard deviations for caregiver marital status. Table 3 displays descriptive data examining caregiver and child sex and race. Table 4 displays a count of the highest caregiver educational level achieved. 
Five (16\%) caregivers reported that they had been previously involved with Child Protective Services while $1(3 \%)$ reported that they were currently involved.

\section{Procedure}

The procedures for the current study remained the same for all participants, regardless of recruitment site, with the exception of the one participant also enrolled in the "Short Term Treatment Outcomes in Community Mental Health Agencies" (IRB Approved: H—24075) study. All families participated in one assessment during pretreatment. After informed consent was obtained from caregivers and assent was obtained from children who were seven-nine years old, data for the assessment were collected. The first assessment consisted of caregivers completing the report measures in approximately 30 to 45 minutes and participating in a 20 minute videotaped observation. Videotaped observations consisted of a 5 minute "warm up" period and each of the three assessment situations of Child-led Play, Parent-led Play, and CleanUp (Eyberg et al., 2005). One observation was not videotaped due to video camera malfunction. This observation was live coded. Report measures were provided to the caregivers and completed in the following order. These measures include demographic information (Caregiver and Child Information Form), the Child Behavior Checklist (CBCL; Achenbach \& Rescorla, 2000, 2001), the Eyberg Child Behavior Inventory (ECBI; Eyberg \& Pincus, 1999), the Parenting Stress Index (PSI; Abidin, 1990), Difficulties in Emotion Regulation Scale (DERS; Gratz \& Roemer, 2004), and the Emotion Regulation Checklist (ERC; Shields \& Cicchetti, 1997). All families were compensated with a $\$ 25$ Walmart gift card for their time and effort. The one participant previously enrolled in the "Short Term Treatment Outcomes in Community Mental Health Agencies" (IRB Approved: H—24075) study, also participated in one assessment during pretreatment but additionally, signed a second consent form for the current 
study. This participant then completed all necessary measures for the current study in the "Short Term Treatment Outcomes in Community Mental Health Agencies" study plus two additional measures (the Difficulties in Emotion Regulation Scale (Gratz \& Roemer, 2004) and the Emotion Regulation Checklist (Shields \& Cicchetti, 1997) for the current study. This family was also compensated with a $\$ 25$ Walmart gift card for their time.

\section{Coding}

All videotaped parent-child play observations were transcribed by undergraduate research assistants who had completed the WVU IRB CITI training. Using the Kappa statistic, at least $25 \%$ of the observations for each of the three structured situations were double coded for reliability. If the Kappa statistic was below $80 \%$, additional training occurred and the three situations were recoded. Undergraduate research assistants primarily coded the videotapes. The primary investigator of this study and another DPICS-trained doctoral student served as the secondary coder.

Coders were trained to reliability in the coding system using the The Abridged Workbook: Coder Training Manual for the Dyadic Parent-Child Interaction Coding System (3rd ed., Fernandez, Chase, Ingalls, \& Eyberg, 2006). Coders were also required to pass the included review quizzes with $80 \%$ or greater correct as well as to consecutively code three training videotapes with $80 \%$ or greater agreement with the primary investigator or another DPICStrained doctoral student for each of the three situations. The current study was approved by the WVU IRB.

\section{Measures}

Demographic form. Caregivers completed a demographic questionnaire that included caregiver age, sex, race, education level, income, occupation, marital and employment status, 
number of individuals currently residing in the home, child's sex, child's date of birth, any medication the child may be receiving and the caregiver's relationship to the child. Caregivers also reported any current or past involvement in child protective services.

Child Behavior Checklist (CBCL). The Child Behavior Checklist (CBCL; Achenbach \& Rescorla, 2000; 2001) is a widely used, standardized parent-report questionnaire designed to assess a variety of maladaptive child emotional and behavioral difficulties. Two separate versions of the measure exist depending upon the child's age. The CBCL has been found to have good psychometric properties including high test-retest reliability for both scales and versions (r $=.87-.92)$ and good internal consistency (.87-.90) on both the internalizing and externalizing subscales. Finally, the externalizing scale has been found to be highly correlated with child conduct problems and externalizing behavior disorders (Achenbach \& Rescorla, 2000). Caregivers of children between the ages of 1.5-5 years completed one version of the CBCL, containing 99 items while caregivers of children between the ages of 6-9 years completed the version for 6-17 year-old children containing 112 items. The CBCL assesses problems in a variety of domains including general symptomology, externalizing symptoms and internalizing behavior. The CBCL total score as well as the internalizing and externalizing subscales were used in analyses in the current study.

Eyberg Child Behavior Inventory (ECBI). The Eyberg Child Behavior Inventory (ECBI; Eyberg \& Pincus, 1999) is a 36 item, caregiver-report measure of the frequency of commonly reported disruptive behavior problems in children between the ages of 2 and 16 years of age. Items are scored using two scales: a seven point likert-type intensity scale to assess the degree of the child's disruptive behavior and a dichotomous, yes/no problem scale where caregivers indicate whether they consider the behavior to be problematic for them. Psychometic 
data for the ECBI yields impressive findings. Internal consistency scores range from .93 for the Problem Scale to .95 for the Intensity Scale (Colvin, Eyberg, \& Adams, 1999). Test-retest reliability statistics range from $.75-.86$ for the intensity scale and $.75-.88$ for the problem scale (Eyberg \& Pincus, 1999). Inter-rater reliability was .86 for the Intensity Scale and .79 for the Problem Scale. The ECBI has demonstrated reliability over an extended period of 10 months for the intensity scale $(r=.75)$. Together, these findings indicate stability and reliability of the measure. The ECBI has also demonstrated concurrent validity with the CBCL externalizing ( $\mathrm{r}=$ $.67)$ and internalizing subscales ( $r=.75)$ with the CBCL, the PSI (Eyberg \& Pincus, 1999) and finally, with observed child negative affect, nonacceptance, and dominance (Webster-Stratton \& Eyberg, 1982). Both the Intensity score and Problem score were analyzed in the current study.

Parenting Stress Index - Short Form (PSI). The Parenting Stress Index - Short Form (PSI:SF; Abidin, 1990) is a caregiver- report measure designed to assess a caregiver's level of stress related to caring for a child between the ages of 1 month and 12 years of age. The measure contains 36 items and three subscales: Parental Distress, Parent-Child Dysfunction, and Difficult Child. The PSI short form has been found to be highly correlated with the longer version of the PSI $(\mathrm{r}=.94)$. The PSI has also demonstrated good test-retest reliability after 3 weeks ( .82 child, .71 parent) and one year (.55 child, .70 parent) (Loyd \& Abidin, 1985), indicating the stability of the measure over time. The current study examined the PSI total score as well as each of the three individual subscale scores.

Difficulties in Emotion Regulation Scale (DERS). The Difficulties in Emotion Regulation Scale (DERS; Gratz \& Roemer, 2004) is a 36-item self-report scale designed to assess emotion dysregulation. The DERS has been used with a variety of clinical and nonclinical populations including re-victimized female inmates (Walsh, DiLillo \& Scalora, 2011), 
patients with borderline personality disorder (Gratz, Lacroce, \& Gunderson, 2006) and college students (Gratz \& Roemer, 2004). Six domains of emotion dysregulation are assessed including: (1) nonacceptance to emotional responses, (2) difficulties engaging in goal-directed behavior, (3) difficulties in impulse control, (4) lack of emotional awareness, (5) limited access to emotion regulation strategies, and (6) lack of emotional clarity. Participants were asked to determine how often each item applies to themselves with items ranging from $1=$ almost never $(0-10 \%$ of the time) to $5=$ almost always (91-100\% of the time) (Gratz \& Roemer, 2004). Higher scores indicate greater difficulty with emotion regulation. Scores are reported as a total score ranging from 36-180 as well as subscale scores of varying ranges. The DERS has been empirically shown to have high overall internal consistency $(\alpha=.93)$, sufficient test-retest reliability (.88), and good construct and predictive validity (Gratz \& Roemer, 2004; Gratz \& Tull, in press).In the current study, the overall score as well as each of the six subscales were examined.

Emotion Regulation Checklist (ERC). The Emotion Regulation Checklist (ERC;

Shields \& Cicchetti, 1997) is a 24 item parent report measure targeting child emotion regulation processes and emotionality. The measure takes about 10 minutes to complete and is comprised of two subscales: (a) Lability/Negativity which is designed to assess child negative reactivity, emotional intensity, and dysregulated negative affect and (b) Emotion Regulation which includes relating to adaptive regulation, empathy, and emotional self-awareness. Scores from both subscales are combined to produce a measure of emotion regulation and dysregulation (Shields \& Cicchetti, 1997; Suveg \& Zeman, 2004). The subscales have been found to be significantly correlated $(\mathrm{r}=-.50)$. Reliability coefficients are high for both the overall measure $(.89)$ as well as the two subscales (Lability/Negativity $=.96$, Regulation $=.83)$. Convergent validity has also been established using a behavioral observation rating system to determine children's emotion 
regulation abilities (Shields \& Cicchetti, 1997). The current study analyzed both the ERC total score as well as individual subscale scores.

Dyadic Parent-Child Interaction Coding System (DPICS). The Dyadic Parent-Child Interaction Coding System, Third Edition (DPICS- III; Eyberg, Nelson, Duke, \& Boggs, 2005) is an observational system designed to examine caregiver and child behavior in three independent situations. The situations last 5 minutes each and follow a structured format in which first, the child picks an activity and leads the play (Child Led Play -CLP). Then, the parent is instructed to take control and lead the play (Parent- Led Play - PLP). Finally, the parent instructs the child to clean up the toys without the parent's assistance (Clean-Up).

Reliability statistics indicated that the DPICS is able to differentiate between children with conduct difficulties and typical children (Eyberg, Nelson, Duke, \& Boggs, 2005). Inter-rater reliability for parent behaviors and child behavior was .91 and .92 , respectively (Robinson \& Eyberg, 1981). Eyberg et al. (2005) evaluated the test-retest reliability of parent praise and negative talk statements during Parent-led Play and Clean Up situations and found that these codes remain stable over a one-week period (Eyberg et al., 2005). The current study specifically examined the rate of caregiver negative talk (i.e., instances in which a caregiver expresses verbal disapproval for a child's behavior, activity or speech, Eyberg et al., 2005), caregiver commands (i.e., instances in which a caregiver verbally states a specific direction in statement or question form that requires the child to perform some action, Eyberg et al., 2005) and percentage of child compliance to parental commands (i.e., instances in which the child begins to engage in the requested action within five seconds of the stated command, Eyberg et al., 2005) across all three structured situations (CLP, PLP and CU). Child percent compliance was calculated by dividing the rate of child compliance by the total commands. 
Prior to data analysis, Kappa statistics were calculated for caregiver DPICS dependent variables. Two Kappa statistics were calculated. The first included caregiver commands, negative talk and other (not commands or negative talk) statements. The second included compliance (comply/non-comply) to all commands coded by both raters. Kappa values ranged from .82-.98 for the command/negative talk/other composite and from $.81-1.0$ for the compliance composite.

\section{Results}

Missing data were analyzed and completed according to directions in each measure's designated manual. One child was missing 1 item on the ECBI, two children were missing one item on the PSI, and one child was missing two items on the PSI. Three children were missing one item on the ERC. Zero items were missed on the DERS or CBCL. Following appropriate imputation of missing data, all measures were included in analysis.

Preliminary analyses examined possible violations of normality, linearity, multicollinearity and homoscedasticity. All measures (CBCL, ECBI, PSI, ERC, DERS) and each of their respective subscales were normally distributed. Although the DPICS compliance composite was normally distributed, a scatterplot revealed that it was non-linear. The DPICS negative talk code was not normally distributed and was non-linear. Following an initial log10 transformation, each original score of zero was incorrectly eliminated. Therefore, given the continuous nature of the variable, one point was added to each original score and the $\log 10$ transformation was recalculated. Following this transformation, the normality assumption was met. 
In the current study, the strength of all Pearson correlational analyses were analyzed and will be discussed according to Cohen (1988). Cohen (1988) categorized a correlation coefficient of $\mathrm{r}=.10$ as "small", $\mathrm{r}=.30$ as "medium" and $\mathrm{r}=.50$ as "large".

The analysis for the first research question compared emotion dysregulation in the current sample of caregivers and children to a non-referred sample of adults (Gratz \& Roemer, 2004) and children (Blandon, Calkins, Keane \& O'Brien, 2008; Graziano, Reavis, Keane \& Calkins, 2007) respectively. To compare the means of the current sample of caregivers on the DERS to a non-referred sample of adults (Gratz \& Roemer, 2004), a one-sample t-test was conducted. The sample was selected because it represents a typical adult sample of college students $(M=23.10$, $\mathrm{SD}=5.67)$ with a similar racial make-up as the current sample. Although average DERS scores were calculated separately for males and females in the original study, a combined average was re-calculated for the current analysis. Means and standard deviations of DERS total scale scores in the non-referred sample of adults as well as the current sample are presented in Table 5. Caregivers in the current sample did not report higher levels of emotion dysregulation ( $\mathrm{M}=$ $72.38, \mathrm{SD}=21.45)$ than a non-referred sample of adults $(\mathrm{M}=78.72), \mathrm{t}(31)=-1.673, \mathrm{p}=.104$. Results are presented in Table 6.

To compare the means of the current sample of children on each of the ERC subscales (lability/negativity, emotion regulation) to a standardized sample of children (Blandon, Calkins, Keane \& O'Brien, 2008), two separate, one-sample t-tests were conducted. The aformentioned standardized, community-based sample of children was chosen for its demographic similarity to the current sample (Blandon, Calkins, Keane \& O’Brien, 2008). Children in the standardized sample were primarily White/Caucasian, from intact families and came from diverse economic backgrounds. The study utilized a longitudinal design in which the children's emotion regulation 
was assessed once per year when the children were on average four, five and six years old $(\mathrm{M}=$ $4.54(\mathrm{SD}=.28), \mathrm{M}=5.72(\mathrm{SD}=.27)$ and $\mathrm{M}=7.62(\mathrm{SD}=.29)$. Given the mean age of the current sample and the lack of intervention between time points in the standardized sample, the second time point $(\mathrm{M}=5.72)$ in the standardized sample was chosen for comparison.

Means and standard deviations of ERC scores in the standardized sample of children as well as the current sample are presented in Table 5. The children's ERC scores in the current sample reported significantly higher levels of lability/negativity according to the lability/negativity subscale $(\mathrm{M}=2.55, \mathrm{SD}=.55)$ than the standardized sample of children, $\mathrm{t}(31)=$ $6.562, \mathrm{p}=.000$. Children in the current sample were also reported to have significantly lower levels of emotion regulation on the emotion regulation subscale $(\mathrm{M}=3.12, \mathrm{SD}=.33)$ than the standardized sample of children, $\mathrm{t}(31)=-3.684, \mathrm{p}=.001$. Results are presented in Table 6 . Means were not available for the total ERC score and therefore, a one sample t-test comparing the ERC total score in the current study to a standardized sample of children was not conducted.

The second research question examined the relation between caregiver emotion dysregulation scores and the amount of negative talk spoken by the caregiver across all three DPICS situations (CLP, PLP and Clean-Up). Table 7 displays the means and standard deviations for the frequency of negative talk across all three DPICS situations. To examine the relationship between caregiver emotion dysregulation and caregiver negative talk, a bivariate Pearson correlation (between DERS total score and amount of negative talk across all three DPICS play situations) was performed. Higher scores on the DERS indicate higher levels of emotion dysregulation while higher scores on the DPICS negative talk indicate more caregiver negative speech during the parent-child interaction. 
Caregiver total emotion dysregulation scores were not significantly correlated with negative statements spoken by caregivers. Caregiver DERS scores were not significantly correlated with DPICS negative talk scores, $\mathrm{r}=.258, \mathrm{p}=.154$. As previously discussed, a $\log 10$ transformation was completed to fulfill the assumption of normality. Following a square root transformation, the variable remained non-linear. It was concluded that the relationship between caregiver emotion dysregulation and caregiver negative talk was non-significant and cannot be interpreted.

The third research question examined the relation between caregiver emotion dysregulation scores and caregiver overall stress levels. Table 7 displays the means and standard deviations for caregiver emotion dysregulation scores on the DERS including the total score and each of the six subscale scores (e.g., non-acceptance of emotional responses, difficulties engaging in goal directed behavior, impulse control difficulties, lack of emotional awareness, limited access to emotion regulation strategies, lack of emotional clarity). Table 7 also displays the means and standard deviations for parenting stress scores on the PSI including the total score and each of the three subscale scores (e.g., parental distress, parent-child dysfunctional interaction, difficult child). To examine the relationship between caregiver emotion dysregulation and parental stress, three separate bivariate Pearson correlations (between DERS total score and each of the three PSI subscale scores - Parental Distress, Parent-Child Dysfunction and Difficult Child) were performed. Additionally, to examine the relationship between caregiver emotion dysregulation and total parenting stress, a final bivariate Pearson correlation (between DERS total score and PSI total score) was performed. Higher scores on the DERS indicate higher levels of emotion dysregulation while higher scores on the PSI indicate higher levels of parental stress. Results can be found in Table 8 . 
Caregiver total emotion dysregulation scores were significantly correlated with caregiver stress on the PSI. A significant, large, positive correlation existed between caregiver emotion dysregulation and parental distress $r=.776, p=.000$, a significant, medium, positive correlation existed between caregiver emotion dysregulation and parent-child dysfunction $r=.497, \mathrm{p}=.004$, and a significant, medium, positive correlation existed between caregiver emotion dysregulation and scores on the Difficult Child $\mathrm{r}=.398, \mathrm{p}=.024$ subscale. Caregiver DERS scores were also significantly correlated with PSI total scores in which a large, positive correlation, $\mathrm{r}=.654, \mathrm{p}=$ .000 was found. These findings indicate that higher scores on the DERS were associated with higher levels of parenting stress according to the PSI.

The fourth research question examined the relation between caregiver emotion dysregulation scores and child level of disruptive behavior problems. Table 7 displays the means and standard deviations for the CBCL total score as well as the internalizing and externalizing subscale scores. To examine the relationship between caregiver emotion dysregulation and child disruptive behavior problems, two separate bivariate Pearson correlations (between DERS total score and the CBCL internalizing and externalizing subscales, respectively) were performed. Additionally, to examine the relationship between caregiver emotion dysregulation and total child behavior problems, another bivariate Pearson correlation (between DERS total score and CBCL total score) was performed. Results are displayed in Table 9. Next, means and standard deviations for the intensity score and problem score on the ECBI were calculated and are displayed in Table 7. A Pearson correlation was performed to examine the relationship between caregiver emotion dysregulation and the child's intensity score on the ECBI. Another Pearson correlation was conducted to examine the relation between caregiver emotion dysregulation and the child's problem score on the ECBI. Results of both correlations are displayed on Table 10. A 
final Pearson correlation was calculated to examine the relation between caregiver emotion dysregulation and the child's rate of compliance to DPICS commands. Higher scores on the DERS indicate higher levels of emotion dysregulation while higher scores on the CBCL and ECBI indicate higher levels of child behavior problems. Finally, higher scores on the DPICS compliance measure indicate higher levels of child compliance. Table 7 displays the means and standard deviations of the DPICS compliance composite.

Caregiver total emotion dysregulation scores were significantly correlated with child behavior problems according to the CBCL. Significant, medium, positive correlations existed between caregiver emotion dysregulation and scores on both the internalizing $\mathrm{r}=.439, \mathrm{p}=.012$ and externalizing $\mathrm{r}=.396, \mathrm{p}=.025$ subscales of the CBCL. A significant, large, positive correlation was found between caregiver emotion dysregulation and total child behavior problems $\mathrm{r}=.512, \mathrm{p}=.003$. These correlations indicated that higher scores on the DERS were associated with higher levels of child internalizing, externalizing and total behavior problems on the CBCL.

A trend toward statistical significance existed for the relation between caregiver total emotion dysregulation and child behavior problems according to the intensity score on the ECBI $\mathrm{r}=.337, \mathrm{p}=.060$. Although non-significant, this relationship was similar to the correlation found between the CBCL externalizing subscale and the DERS. Caregiver emotion dysregulation was not significantly related to caregiver ratings of number of child behavior problems according to the problem score on the ECBI $r=.284, p=.116$. A final Pearson correlation between caregiver emotion dysregulation and child compliance to DPICS commands $r=.-.158, \mathrm{p}=.387$ was nonsignificant and cannot be interpreted. 
The fifth research question addresses the relationship between caregiver emotion dysregulation and child emotion regulation. See Table 7 for the means and standard deviations of the DERS total and subscale scores and Table 5 for the ERC subscale scores. Table 7 also displays the mean and standard deviation of the ERC total score. To examine the relationship between caregiver emotion regulation and child emotion regulation, three bivariate Pearson correlations (between DERS total score and the ERC total score, DERS total score and ERC Emotion Regulation Subscale and DERS total score and ERC Lability/Negativity subscale) were performed. Higher scores on the DERS indicate higher levels of emotion dysregulation. Higher scores on the ERC Lability/Negativity subscale indicate higher levels of lability and negativity while higher scores on the Emotion Regulation subscale indicate better emotion regulation abilities. Results are displayed on Table 11.

Caregiver emotion dysregulation total scores were not significantly correlated with child emotion regulation ERC total scores $\mathrm{r}=-.253, \mathrm{p}=.163$, the emotion regulation subscale of the ERC $\mathrm{r}=-.058, \mathrm{p}=.754$ or the lability/negativity subscale score $\mathrm{r}=.276, \mathrm{p}=.127$ and therefore, cannot be interpreted.

In summary, although some of the aforementioned correlations did not meet statistical significance, each was in the hypothesized direction. It is possible that a future study with a larger sample size may find significant correlations between these variables.

A sixth research question aims to determine the proportion of variance in caregiver emotion dysregulation (DERS total score) that can be accounted for by the following five variables: PSI Parental Distress subscale, CBCL total score, DPICS negative talk, ECBI intensity score and ERC total score. A linear multiple regression analysis was performed in which all five variables, regardless of significance, were simultaneously entered into the regression analysis. 
Given the abnormal nature of the DPICS negative talk variable, the previously $\log 10$ transformed version of the variable was substituted for the untransformed variable in analysis. The data were reviewed for missing cases and violation of assumptions before analysis. No missing data were present. The total variance explained by the model as a whole was $55.8 \%, F(5,26)=8.82, \mathrm{p}<$ .00. In the model, only one predictor, the Parenting Distress subscale of the Parenting Stress Index significantly contributed to the model as evidenced by a high Beta value (beta $=.747, \mathrm{p}<$ $.00)$. Each of the four remaining factors (CBCL total score, $\log 10$ DPICS negative talk, ECBI Intensity Score and ERC total Score) did not significantly contribute to the model. Collinearity statistics revealed problems with collinearity with the CBCL total score, ECBI intensity score and ERC total score. Results, including collinearity diagnostics are presented in Table 12.

A final research question aims to determine the proportion of variance in child emotion dysregulation (ERC total score) that can be accounted for by the following five variables: PSI Parental Distress subscale, CBCL total score, DPICS negative talk, ECBI intensity score and DERS total score. A linear multiple regression analysis was performed in which all five variables, regardless of significance, were simultaneously entered into the regression analysis. Given the abnormal nature of the DPICS negative talk variable, the previously log 10 transformed version of the variable was substituted for the untransformed variable in analysis. The data were reviewed for missing cases and violation of assumptions before analysis. No missing data were present. The total variance explained by the model as a whole was $67.9 \%, \mathrm{~F}(5,26)=14.09, \mathrm{p}=$ .000. In the model, two predictors, the CBCL total score and ECBI Intensity Total Score significantly contributed to the model as evidenced by high beta values (beta $=-.480, \mathrm{p}=.014$; beta $=-.516, p=.003$ respectively). Each of the three remaining factors (DERS total, Parenting Stress Index - Parental Distress subscale and $\log 10$ DPICS negative talk) did not significantly 
contribute to the model. Collinearity statistics revealed problems with collinearity with the DERS total score and significant problems with the CBCL total score and the Parenting Stress Index - Parental Distress subscale. Results, including collinearity diagnostics are presented in Table 13.

\section{Discussion}

The purposes of the present study were to (1) explore the role of caregiver emotion regulation in parent training by attempting to understand if parents who are referred for parent training have difficulty with emotion regulation and (2) recognize the degree to which these difficulties correlate with levels of parental stress, negative interactions, and children's behavior problems at the beginning of treatment. The current sample of clinically-referred caregivers was not found to be more emotionally dysregulated than a non-referred sample of university adults. However, the current sample of children was found to be more emotionally negative, possess greater emotional lability and less emotion regulation as compared to a typical sample of community children. Caregiver emotion dysregulation was not found to be significantly correlated with caregiver negative talk during a behavioral observation task. However, caregiver emotion dysregulation was found to be significantly correlated with caregiver overall stress scores as well as subscale scores on the Parental Stress Index subscales. Caregiver emotion dysregulation was also found to significantly correlate with child disruptive behavior problems on the CBCL. A statistical trend toward significance was detected between caregiver total emotion dysregulation and child behavior problems according to the ECBI intensity score. However, caregiver emotion dysregulation was not significantly correlated with the ECBI problem score or DPICS behavioral observations of child compliance. Caregiver emotion dysregulation was not significantly correlated with the child emotion regulation. The PSI 
Parental distress subscale emerged as the only significant predictor of caregiver emotion regulation, while child behavior problems emerged as the only significant predictors of child emotion regulation.

\section{Caregiver Emotion Regulation}

The results of this study indicate that caregivers in the current sample were not more emotionally dysregulated as compared to a non-referred sample of adults according to the DERS. It is important to note that the standardization sample, although spanning a large age range, was primarily college-aged students $(\mathrm{M}=23.10, \mathrm{SD}=5.67)$. The current sample of caregivers, however, were notably older $(\mathrm{M}=32.59, \mathrm{SD}=8.53)$. It is well documented that emotion regulation abilities generally improve with age (Charles \& Carstensen, 2013). Some research has demonstrated that older adults report fewer negative emotions as compared to younger adults, which may be the result of increased cognitive coping abilities (Wang \& Saudino, 2011). Older adults are also more likely to respond more positively to stressors (Almeida, 2005; Wang \& Saudino, 2011). Long-term follow up of patients diagnosed with Borderline Personality Disorder (Paris \& Zweig-Frank, 2001), Antisocial Personality Disorder (Black, Baumgard \& Bell, 1995) and Bi-Polar Disorder (Diler, Birmaher \& Miklowitz, 2010) found that despite their inherent difficulties with emotion regulation, these patients revealed improvement in symptomology across time. Therefore, it is not surprising that the current, older sample of caregivers would report better emotion regulation abilities as compared to a younger, college-aged sample. It is also possible that given the self-report nature of the DERS, adults in the current sample may have lacked insight and awareness into their emotional states, and therefore may have had difficulty accurately identifying and rating their emotions (Gratz \& Roemer, 2004). Additional research supports this hypothesis indicating that caregivers of children with conduct problems 
demonstrate less awareness and understanding of their emotions (Katz \& Windecker-Nelson, 2004). Finally, it is possible that caregivers felt calm and relatively well-regulated as they completed the DERS measure, which may have contributed to a more positive view of their emotion regulation abilities. Perhaps, if caregivers had been asked to participate in a negative emotion induction task prior to the completion of the DERS, such negative emotions may have been more salient which in turn may have influenced reporting. Methodologically, social desirability and participant bias may have skewed caregivers' report of negative emotions. Parents being observed and coded while playing with their child may be influenced to portray themselves in a favorable light.

\section{Child Emotion Regulation}

Children in the current sample were found to be more emotionally negative, possess greater emotional lability and less emotion regulation as compared to a typical sample of children. Such results are in line with previous research indicating that children with disruptive behavior and conduct disorders frequently experience difficulty with emotion regulation (Macklem, 2008). Specifically, children with externalizing disorders have difficulty suppressing negative emotions, identifying emotional cues and often exhibit more extreme emotions more frequently as compared to typical children (Macklem, 2008). Children with externalizing disorders may use aggression, instead of more appropriate methods, to cope with negative emotions (Macklem, 2008). Roll, Koglin and Petermann (2012) compiled a series of longitudinal studies to investigate the relationship between self-reported and behavioral measures of emotion regulation and aggression/externalizing symptoms in childhood. Results showed that deficits in emotion regulation were clearly linked to childhood aggressive symptoms. One aspect of emotion regulation, effortful control, or the ability to inhibit reacting to environmental triggers, 
has been found to be a key element of emotion regulation difficulties in children with externalizing disorders as compared to their same-age peers (Macklem, 2008; Eisenberg et al., 2005). In addition to deficits in effortful control, children with externalizing behavior problems, and especially those with Attention Deficit Hyperactivity Disorder, may also exhibit difficulties with attention shifting and inhibitory control. These problems with focus and self-control may in turn increase the likelihood that these children react negatively or impulsively when told to change activities by adults (Eisenberg et al., 2005). It is important to note that child emotion regulation was measured via caregiver self-report. Given the high rate of oppositional defiant and conduct disorder in clinically-referred children and the fact that caregivers in the current sample sought out and had recently entered clinical treatment for their child's disruptive behavior, it is not surprising that such caregivers rated their children with significantly more emotion regulation problems than a non-clinical sample (Keenan \& Wakschlag, 2004).

\section{Caregiver Emotion Dysregulation and Caregiver Negative Talk}

Caregiver self-reported emotion dysregulation was not significantly correlated with caregiver negative talk statements across all three DPICS play situations. Past literature indicates that negative parenting behaviors such as yelling and critical statements are more likely to occur during interactions with children with noncompliant, aggressive and oppositional behavior (Mammen, Kolko, \& Pilkonis, 2003). Negative and increasingly coercive parent-child interactions common between children with behavior problems and their caregivers have also been associated with negative verbal exchanges between parents and children (Dishion, French, \& Patterson, 1995; Eddy, Leve, \& Fagot, 2001). There are a number of explanations why a nonsignificant correlation between caregiver emotion dysregulation and caregiver negative talk may have been observed in the current study. To begin, children provided with undivided caregiver 
attention during DPICS play situation tasks may be less likely to misbehave than children who had not received such direct attention. In turn, caregivers may have spoken less negatively to children during the DPICS tasks. Using a sample of physically abusive parents, a population commonly associated with difficulties in emotion regulation (Howes, Cicchetti, Toth, \& Rogosch, 2000), Lau, Valeri, McCarty and Weisz (2006) coded a series of structured parentchild interactions for content and emotional affect. Abusive parents were not significantly different from non-abusive parents in terms of hostility, detachment, affective tone or disengagement. In addition, externalizing behavior of abused children did not differ from comparison children according to independent raters. Methodologically, the authors explained that a number of laboratory-type procedures were used that may have influenced the ecological validity of the data (Lau, Valeri, McCarty \& Weisz, 2006).

Although the current study was conducted primarily in participants' homes, there remained laboratory-type procedures that could have resulted in difficulties with ecological validity. Prior to each play situation, caregivers were given instructions and novel toys were provided. In addition, all situations were videotaped, which may have increased the likelihood that caregivers (a) would be more self-conscious and (b) would speak to their child in more socially desirable ways. In addition, the presence of novel toys and a new person in the child's environment (the experimenter) may have decreased the likelihood of child misbehavior. Finally, as authors noted in the aforementioned study, the use of structured play situations may have detracted from a more natural day to day parent-child interaction in which a caregiver would have spoken critically to his or her child. Therefore, the individualized, child-centered attention provided by caregivers in addition to ecological validity variables may help to explain the 
nonsignificant relationship between caregiver emotion dysregulation and caregiver negative talk statements during the DPICS play situations.

\section{Caregiver Emotion Dysregulation and Parenting Stress}

Caregiver emotion dysregulation was significantly related to overall caregiver stress, parental distress, caregiver ratings of parent-child dysfunction and caregiver ratings of their child as a difficult child. These findings are consistent with previous literature indicating that parents of children with multiple behavior problems experience significantly elevated levels of parenting stress across all subscales of the Parenting Stress Index (PSI; Abidin, 1990; De Bruyne et al., 2009). Although the correlational nature of the analysis makes it impossible to determine the directionality of the relationship between parenting stress and caregiver emotion dysregulation, a number of explanations are plausible. To begin, it is important to note that both measures of caregiver stress and emotion dysregulation were based on self-report and were completed by the

same individual. Therefore, the statistical likelihood of shared method variance high. Regardless, it may be that previously emotionally dysregulated caregivers are more susceptible to experiencing high levels of parenting stress given existing deficits in seeking out and utilizing adaptive coping strategies (Deater-Deckard, 2004). Dysregulated caregivers may also lack sensitivity (Joinson, Heron, von Gontard, Butler, Golding, \& Emond, 2008) and responsiveness (Davidov \& Grusec, 2006) during interactions with their child, which may in turn, impair their ability to cultivate positive, successful parent-child interactions (Deater-Deckard, 2004). Alternatively, caregivers experiencing high amounts of parenting stress may be more emotionally dysregulated. From this perspective, parenting stress may weaken a caregiver's emotional resources, impairing his or her ability to successfully regulate emotions. 
Although the experience of parenting stress may differ across individual caregivers, it is likely that the conceptualization of parenting stress may overlap considerably with the construct of emotion dysregulation in its focus on an individual's perceived lack of control over his or her internal and external environment (Deater-Deckard, 2004; Gratz \& Tull, in press, Wang \& Saudino, 2011). Additionally, many of the same mechanisms involved in successful coping with stress are also involved in successful emotion regulation (Wang \& Saudino, 2011).

Physiologically, stress has been shown to activate the hypothalamic-pituitary-adrenal (HPA) axis which is associated with emotion regulation as well as cortisol levels (Wang \& Saudino, 2011; Zimmermann \& Stansbury, 2004). Neurologically, the prefrontal cortex is involved with both the processing and regulation of stress and affective experiences (Davidson \& Irwin, 1999) Therefore, highly stressed caregivers may experience higher levels of negative emotions such as anxiety, sadness, anger and guilt (Lazarus, 1999). Although not directly tested, a variety of third variable mechanisms may mediate or moderate the strong link between caregiver emotion dysregulation and parenting stress in the current sample of caregivers. Financial stress, caregiver psychopathology (Williford, Calkins \& Keane, 2007; Deater-Deckard, 2004) and spousal conflict (Deater-Deckard, 2004) have been closely tied to increased parenting stress. Taken together, it was expected that parental stress and caregiver emotion dysregulation would be significantly associated in the current sample of caregivers of clinically referred children.

\section{Caregiver Emotion Dysregulation and Child Behavior Problems}

The Child Behavior Checklist (CBCL). Caregiver emotion dysregulation was significantly correlated with child behavior problems according to the internalizing and externalizing subscales of the $\mathrm{CBCL}$ as well as the $\mathrm{CBCL}$ total child behavior problem score. 
The current findings in a sample of clinically referred caregivers replicate a previously established relationship between caregiver emotion dysregulation and child behavior problems.

The direction of causality between caregiver emotion dysregulation and child behavior problems is difficult to determine given the moment-by-moment, bi-directional interactions between a caregivers' emotions and a child's behavior (Deater-Deckard, 2004). Some longitudinal research indicates that parental emotion dysregulation as evidenced by expressions of parental anger predicted ongoing difficulties with externalizing behavior problems in children (Denham et al., 2000). Parental negative emotionality has also been associated with higher levels of internalizing behaviors in a sample of low-income children and families (Shaw, Keenan, Vondra, Delliquadri \& Giovannelli, 1997). Parental psychopathology, indicative of difficulties with emotion dysregulation, has also been found to be significantly related to child behavior problems (Cummings, Keller, \& Davies, 2005). Subsequent longitudinal research demonstrated that children's conduct problems, rather than caregiver variables, were causally related to higher levels of conflict in the parent-child relationship demonstrating the influence of child behavior problems on caregiver emotion dysregulation (Anderson, Lytton, \& Romney, 1986).

In addition to the clear relationship between caregiver emotion dysregulation and child behavior problems, it is important to note that emotionally distressed caregivers may recognize their child's misbehavior more often, perceive their children's misbehavior to be more severe and exhibit less tolerance for children's misbehavior (Deater-Deckard, 2004). Decreased tolerance for children's misbehavior has been significantly linked to increased parental perceptions of child behavior as problematic (Brestan, Eyberg, Algina, Johnson \& Boggs, 2003) which may in turn lead caregivers to over-report the intensity of child behavior problems (Deater-Deckard, 2004). This finding has been replicated in a sample of maltreating caregivers 
indicating a tendency for emotionally dysregulated, highly stressed caregivers to misrepresent the severity of child behavior problems (Lau, Valeri, McCarty \& Weisz, 2006).

Child emotion regulation may also account for considerable variation in the relationship between caregiver emotion regulation and child behavior problems (Chang, Swartz, Dodge \& McBride-Chang, 2003). Specifically, negative, harsh and punitive parenting strategies, indicative of difficulties in emotion regulation, have been found to negatively impact children's emotion regulation which in turn may disrupt a child's ability to control his or her emotions (Chang, Swartz, Dodge \& McBride-Chang, 2003). It has been postulated that such children carry emotionally dysregulated strategies to subsequent environments in which they then engage in inappropriate or maladaptive behavior (Chang, Swartz, Dodge \& McBride-Chang, 2003).

Finally, despite the strong relationship between caregiver emotion dysregulation and child behavior problems in the current sample, it is important to recognize the considerable influence of parenting stress in this correlation. Extensive research has demonstrated the predictive and meditational impact of parenting stress as a cause and outcome of the relationship between parental emotion regulation and child behavior problems (Deater-Deckard, 2004).

The Eyberg Behavior Inventory (ECBI). A trend toward statistical significance existed for the relationship between caregiver total emotion dysregulation and child behavior problems according to the intensity score on the ECBI $(r=.337, \mathrm{p}=.060)$. Given the previously described association between caregiver emotion dysregulation and child behavior problems, this finding may be due to the small size of the current sample. Given a larger sample and greater power in future research, this trend may be significant.

Surprisingly, caregiver emotion dysregulation was not significantly related to caregiver ratings of number of child behaviors perceived as problematic according to the problem score on 
the ECBI. A number of potential explanations may help to clarify this finding. It may be that both emotionally dysregulated caregivers and emotionally regulated caregivers recognize certain behaviors as problematic or non-problematic when measured on a forced choice, dichotomous scale (i.e., yes/no). As noted in the previous analysis, it is the intensity to which emotionally dysregulated caregivers and emotionally regulated caregivers rated these behaviors that may be indicative of their perceived ability to emotionally cope with such behaviors. Other variables such as the presence of marital conflict (Erath, Bierman \& the Conduct Problems Prevention Research Group, 2006), punitive parenting (Dodge, Pettit \& Bates, 1994) and socio-economic disadvantage (Dodge, Pettit \& Bates, 1994) have been related to childhood conduct problems. Such variables may indirectly measure a larger variety of family functioning variables that better encompass the variety of factors leading a caregiver to rate a child's behavior as problematic (Lindahl, 1998).

Child Compliance. A final Pearson correlation revealed a nonsignificant relationship between caregiver emotion dysregulation and the child's rate of compliance to DPICS commands. This finding is also surprising given the established, negative association between caregiver emotion regulation and child behavior problems (DeBruyne et al., 2009) as well as the positive association between child emotion regulation and child compliance (Stringaris, Maughan \& Goodman, 2010). A number of explanations may help explain this finding. The previously discussed ecological validity limitations of the DPICS in the current study may have positively influenced parent-child interactions and child compliance across the three structured situations. Dumas, Lemay, and Dauwalder (2001) examined the dynamics of mother-child interaction patterns in two samples of children and caregivers - one referred for disruptive behavior and a second group of non-referred children. Child compliance was coded over six, 1- 
hour home visits over the course of 2-3 weeks while dyads engaged in typical family activities and interactions. Results indicated that caregivers and children in the referred group engaged in repeated cycles of attempted caregiver control and child noncompliance. However, mothers in the non-referred comparison group initiated attempts at control with positivity and were more likely to achieve child compliance. Perhaps, the play-based nature of the DPICS tasks along with the presence of novel toys may have deterred parents and children from entering into the coercive interaction patterns typically associated with more frequent commands and child noncompliance (Forgatch \& Patterson, 2003; Gauvain \& Perez, 2008). As a result, children in the current sample may have exhibited more noncompliant behavior if caregiver-child interactions had been measured during typical, daily tasks rather than in structured, play-based situations.

Parpal and Maccoby (1985) examined child compliance to caregivers under three conditions (1) a noninteractive condition in which caregivers were instructed to complete paperwork while children played nearby (2) a free play condition in which caregivers and children were told to play as they naturally do at home and (3) a responsive condition in which mothers' received a short training on child-directed play skills (i.e., imitation, behavior descriptions and avoidance of questions, commands and critical talk) and were instructed to practice such skills with the child in the week prior to the experiment. Results indicated that the responsive and non-interactive conditions were associated with better child compliance than the free play condition. Given the fact that families in the current study may have received up to three sessions of parent training prior to study procedures, it is likely that many caregivers had received some level of instruction, similar to that in the responsive condition prior to the initiation of study procedures. In addition, the DPICS instructions (“...follow his/her lead and play along with him/her") begin by instructing parents to allow the child to control the play 
situation. Similarly, the responsive condition in the aforementioned study also instructed caregivers to allow the child to control the play interaction. Therefore, this initial interaction may have set a positive tone for the remaining two DPICS situations (parent-directed interaction and clean up), which in turn may have led to overall higher than usual levels of child compliance. Although it was not directly measured, anecdotal evidence indicated that overall, caregivers were 'surprised' by their child's compliant behavior during the DPICS situations. Finally, the children may have also enjoyed receiving their caregivers' undivided attention while playing with toys, which in turn may have resulted in increased cooperation, more positive emotions and increased maternal responsiveness than expected. Such variables have been associated with increased child compliance (Dumas, LaFreniere \& Serketich, 1995; Parpal \& Maccoby, 1985).

Although all caregivers and children in the current sample had been clinically referred for parent training, only a portion ( $\mathrm{N}=21,65.6 \%)$ of children met or surpassed the clinical cutoff for behavior problems according to the ECBI. Therefore, despite potentially emotionally dysregulated caregivers, some children in the sample may not have experienced clinically significant difficulties with compliance according to caregiver report. Finally, additional correlations between DPICS child compliance and the CBCL total problem score and ECBI intensity score revealed non-significant relations between variables. Such findings indicate that the demand characteristics of the situation may have interfered with the validity of the DPICS child compliance (see Table 14).

\section{Association between Caregiver Emotion Regulation and Child Emotion Regulation}

Caregiver emotion dysregulation total scores were not significantly correlated with child emotion regulation total scores, lability/negativity subscale score or the emotion regulation subscale score. Despite extensive literature documenting the biological and environmental 
correlates inherent in the transmission of emotion regulatory strategies between parents and children (Carrère \& Bowie, 2012; Marziali, Damianakis \& Trocmé, 2003; Morris et al., 2007; Schmitz, Fulker, Plomin, Zahn-Waxler, \& DeFries, 1999), a number of explanations may help illustrate the lack of a significant association between caregiver emotion regulation and child emotion regulation in this investigation. To begin, caregiver emotion dysregulation was only assessed in the current study according to caregiver self-report. However, it has been demonstrated that parents of children with behavior problems have been found to demonstrate less emotional awareness and understanding of their emotions and devote less time to helping their children understand and control their emotions (Katz \& Windecker-Nelson, 2004). Therefore, emotion dysregulation may interfere with parenting as it has been found to interfere with other significant relationships such as marriages (Carstensen, Gottman, \& Levenson, 1995). Maltreating caregivers frequently mis-label and inappropriately react to others' emotional expressions and concurrently demonstrate less understanding of their child's emotions (Marziali, Damianakis \& Trocmé, 2003). Taken together, this information indicates that caregivers of children with behavior problems may lack the emotional awareness, insight and emotional identification necessary to accurately report their own as well as their child's emotion regulation.

Given the unique status of the current sample of caregivers as recently referred to parenttraining for child disruptive behavior problems, caregivers may have intentionally or unintentionally under-reported their own emotion regulatory difficulties so as to position their child as 'the problem.' A larger sample size, multiple methods, multiple raters, informants and the inclusion of a more stressful task to elicit emotion dysregulation in caregivers and children may have increased the likelihood of finding an association between caregiver and child emotion regulation and improved the accuracy of results. 


\section{Predicting Caregiver Emotion Dysregulation}

A linear multiple regression analysis predicting caregiver emotion dysregulation revealed a significant overall model explaining $55.8 \%$ of the total variance in the DERS. Only one predictor, the Parenting Distress subscale of the Parenting Stress Index significantly contributed to the model, carrying the majority of the variance accounted for by all five predictors. The link between parental distress and emotion dysregulation is well known (Deater-Deckard, 2004). Specifically, parental distress has been said to aggravate parents' psychological vulnerabilities which in turn, may negatively impact the caregivers' emotional ability to cope with the daily stresses involved in caring for a child with behavior problems (Deater-Deckard, 2004). Parental distress is also highly linked with parental depression, a core component of which is emotion dysregulation (Colpin, DeMunter, Nys \& Vandemeulebroecke, 2000; Deater-Deckard, 2004). Emotional distress may encompass more than simply the intensity or frequency of their child's behavior problems. For example, relationship satisfaction, high levels of family conflict, low income, poor housing and less social support have been linked to high levels of parental distress (Deater-Deckard, 2004; Emick \& Hayslip, 1999). Caregivers who must cope with the complex and often unpredictable demands of all of these intertwining factors may have fewer emotional resources and more difficulty controlling their emotions. Therefore, it may be that Parental Distress accounts for a proportion of variance in parental emotion dysregulation over and above the remaining variables entered into this multiple regression (CBCL total score, ECBI Intensity Score, ERC Total Score, DPICS negative talk). The difficulties associated with each of these areas may contribute to a parent's level of distress such that parental distress then predicts overall parental emotion dysregulation. 
Some level of parental distress is common and may even be a potentially adaptive aspect of the parenting role (Deater-Deckard, 2004) as it may help motivate caregiving behavior. However, high self-reported levels of parental distress may be indicative of a parent's inability to successfully manage such negative emotions, which in turn may be indicative of overall difficulties in emotion regulation (Deater-Deckard, 2004). Methodologically, the collinearity present between the parenting distress and emotional dysregulation variables may indicate that the two constructs are measuring a single, larger concept that includes difficulties identifying, processing, coping with and controlling emotional responses. However, an item analysis of the DERS and Parental Distress subscales of the PSI revealed some notable differences between these constructs. The items in the Parental Distress subscale of the Parenting Stress Index primarily measure a parent's level of satisfaction with his or her role as a parent. However, the items on the DERS primarily examine an adult's level of emotional acceptance, awareness and control. Therefore, the high correlation between these two measures may indicate that parental distress is highly related to the broader construct of difficulties with emotional acceptance, awareness and control.

\section{Predicting Child Emotion Regulation}

A second linear multiple regression analysis with simultaneous entry predicting child emotion regulation was conducted and results revealed a significant overall model explaining $67.9 \%$ of the variance accounted for by the ERC. In the model, two predictors, the CBCL total score and ECBI Intensity Total Score significantly contributed to the model. It is well known that children with behavior problems have core deficits in emotion regulation as evidenced by difficulty using their emotions to assist them in problem solving and communicating their feelings (Dodge \& Coie, 1987; Salmon, Dadds, Allen \& Hawes, 2009). Specifically, children 
with Oppositional Defiant Disorder have difficulty controlling the intensity of both positive and negative emotional expression particularly during stressful experiences (Cole, Michel, \& Teti, 1994; Shields \& Cicchetti, 1998). These children also have difficulty expressing their emotions in socially appropriate ways (Cole, Michel, \& Teti, 1994). They have also been found to possess traits such as irritability, which has been linked to emotional lability, emotional problems and subsequent difficulties in peer relationships (Stringaris \& Goodman, 2009). High levels of emotional lability have been associated with a lack of effortful control, which, as previously discussed, is often present in children with externalizing behavior problems (Macklem, 2008). As a result, such children may impulsively react to negatively emotionally inducing situations and take longer to recover from negative emotional experiences (Dunsmore, Booker, \& Ollendick, 2013; Shields \& Cicchietti, 1998).

Although it is surprising that the remaining three variables (DERS Total Score, DPICS Negative Talk, PSI Parental Distress) did not significantly contribute to the overall model predicting child emotion regulation, multiple explanations may account for this finding. To begin, of the five measures, only the $\mathrm{CBCL}$ and $\mathrm{ECBI}$ were focused on the child. The remaining three variables were parent-based variables. Therefore, it follows that child-focused variables would be most likely to predict a child-focused construct. Given that parents are not able to see children's internal emotion regulation (i.e., cognitive strategies, physiological arousal), it follows that a child's behavior would be the most logical determinant of a parent's ability to assess a child's emotion regulation. Particularly at the time of the referral, parents are particularly aware of their child's behavior problems, as this is often the predominant factor for their entrance into treatment. However, some children did not score in the clinical range on one or both measures of child behavior problems. It is perhaps in these cases that parents determine that their child must 
be more emotionally regulated as compared to children with higher levels of externalizing behavior problems.

Despite these findings, it is important to note that both child emotion regulation and child behavior problems were measured according to parental self-report, which may represent a singular perspective of these variables in light of the parents' own stressors, as well as their emotional identification and regulatory abilities.

\section{Limitations and Future Research}

Although a number of notable findings emerged from analyses of the current sample of recently referred children and caregivers, such results must be considered in light of study limitations. To begin, the current study was based off of a sample of 32 caregiver-child dyads and a small effect size. By including a larger sample of recently referred caregiver-child dyads, future research would have more power to detect significant relationships between variables and predict caregiver and child emotion regulation with greater accuracy. The current study primarily included a sample of mother-child dyads. Given the established association between fathers emotion regulation and child behavior problems (Carrère \& Bowie, 2012), future research should include a larger sample of fathers.

Another limitation of the current study was the variable number of parent-training sessions $(\leq 3)$ that families may have been exposed to prior to evaluation. If possible, it would be ideal for future research to assess families immediately upon referral to parent-training programs. A third limitation of the current study was the reliance upon caregiver report of child emotion regulation and child behavior problems. By including multiple raters of child behavior problems over a longer period of time and during the course of daily routines, researchers may gain a more thorough picture of children's emotional and behavioral functioning. Likewise, subsequent forms 
of evaluation such as a caregiver interview and exposure to a more stressful situation than the DPICS would provide greater insight into caregiver and child emotion regulation. It is perhaps through these additional measures that future research may better illustrate the possible link between caregiver and child emotion regulation which may in turn lead to a more accurate understanding of caregiver emotion regulation.

In conclusion, the current study indicated that children referred to parent training were more emotionally dysregulated as compared to typical, non-referred children. Caregiver emotion dysregulation was significantly related to children's behavior problems and caregiver levels of parental stress. Specifically, parental distress significantly predicted caregiver emotion dysregulation. Children's behavior problems also significantly predicted child emotion regulation. Taken together, these findings indicate the importance of considering emotion regulation as a clinical treatment variable in parent training as well as a particular focus on decreasing caregivers levels' of parental distress, which in turn is likely to improve his or her ability to regulate his or her emotions. Likewise, clinicians may also help motivate caregivers to complete parent training by helping them understand the critical link between a reduction in child behavior problems and an increased ability to control his emotions. 


\section{References}

Abidin, R. R. (1990). Parenting Stress Index / Short Form. Lutz, FL: Psychological Assessment Resources, Inc.

Achenbach, T. M., \& Rescorla, L. A. (2000). Manual for ASEBA preschool forms \& profiles. Burlington, VT: University of Vermont, Research Center for Children, Youth, \& Families.

Achenbach, T. M., \& Rescorla, L. A. (2001). Manual for ASEBA school-age forms \& profiles. Burlington, VT: University of Vermont, Research Center for Children, Youth, \& Families.

Almeida, D.M. (2005). Resilience and Vulnerability to Daily Stressors Assessed via Diary Methods. Current Directions in Psychological Science, 14, 64-68. Retrieved from http://www.jstor.org/stable/2137205

American Psychiatric Association. (2000). Diagnostic and statistical manual of mental disorders (4th ed., text rev.). Washington, DC: Author.

Anderson, K. E., Lytton, H., \& Romney, D. M. (1986). Mothers' interactions with normal and conduct-disordered boys: Who affects whom? Developmental Psychology, 22, 604-609. doi:10.1037//0012-1649.22.5.604

Aseltine, R. H., \& Kessler, R.C. (1993). Marital disruption and depression in a community sample. The Journal of Health and Social Behavior, 34, 237-251. Retrieved from http://www.jstor.org/stable/2137205 
Baker, B. L., Blacher, J., Crnic, K., \& Edelbrock, C. (2002). Behavior problems and parenting stress in families of three-year old children with and without developmental delays. American Journal on Mental Retardation, 107, 433-444.

doi: 10.1352/0895-8017(2002)107<0433:BPAPSI >2.0.CO;2

Bariola, E., Hughes, E. K., \& Gullone, E. (2012). Relationships between parent and child emotion regulation strategy use: A brief report. Journal of Child Family Studies, 21 (3), 443-448. doi: 10.1007/s10826-011-9497-5

Barkley, R. 1998. Attention deficit hyperactivity disorder: A handbook for diagnosis and treatment. (2nd ed.). New York: Guilford.

Barnett, O. W., Fagan, R. W., Booker, J. M. (1991). Hostility and stress as mediators of aggression in violent men. Journal of Family Violence, 6 (3), 217-241. doi: 10.1007/BF00980530

Ben-Porath, D. D. (2010). Dialectical behavior therapy applied to parent skills training: Adjunctive treatment for parents with difficulties in affect regulation. Cognitive and Behavioral Practice, 17, 458-465. doi: 10.1016/j.cbpra.2009.07.005

Black, D. W., Baumgard, C. H., \& Bell, S. E. (1995). A 16- to 45-year follow-up of 71 men with antisocial personality disorder. Comprehensive Psychiatry, 36, 130-40. Retrieved from http://www.ncbi.nlm.nih.gov/pubmed/16923669

Blackburn-Munro, G., \& Blackburn-Munro, R. E. (2001). Chronic pain, chronic stress and depression: Coincidence or consequence? Journal of Neuroendocrinology, 13, 1009_ 1023. doi: 10.1046/j.0007-1331.2001.00727. 
Blandon, A. Y., Calkins, S. D., Keane, S. P., \& O’Brien, M. (2008). Individual differences in trajectories of emotion regulation processes: The effects of maternal depressive symptomatology and children's physiological regulation. Developmental Psychology, 44, 1110-1123. doi: 10.1037/0012-1649.44.4.1110

Bloch, L., Moran, E. K., \& Kring, A. M. (2009). On the need for conceptual and definitional clarity in emotion regulation research. In A. M. Kring \& D. Sloan (Eds.), Emotion Regulation and Psychopathology (pp. 88-104). New York: Guilford Press.

Bonn-Miller, M. O., Vujanovic, A. A., Boden, M. T., \& Gross, J. J. (2011). Posttraumatic stress, difficulties in emotion regulation, and coping-oriented marijuana use. Cognitive Behavior Therapy, 40, 34-44. doi: 10.1080/16506073.2010.525253

Brestan, E.V., Eyberg, S.M., Algina, J., Johnson, S.B., \& Boggs, S.R. (2003). How annoying is it? Defining parental tolerance for child misbehavior. Child \& Family Behavior Therapy, 25, 1-15. doi: 10.1300/J019v25n02_01

Brockmeyer, T., Bents, H., Holtforth, M. G., Pfeiffer, N., Herzog, W., \& Friederich, H. (2012). Specific emotion regulation impairments in major depression and anorexia nervosa. Psychiatry Research, 200 (2-3), 550-553. doi: 10.1016/j.psychres.2012.07.009

Buckholdt, K. E., Parra, G. R., \& Jobe-Shields, L. (2010). Emotion dysregulation as a mechanism through which parental magnification of sadness increases risk for binge eating and limited control of eating behaviors. Eating Behaviors, 11 (2), 122-126. doi: 10.1016/j.eatbeh.2009.10.003

Calkins, S.D., \& Hill, A. (2006). Caregiver influences on emerging emotion regulation: Biological and environmental transactions in early development. In J.J. Gross (Ed.), Handbook of emotion regulation (pp. 229-248). New York: Guilford Press. 
Calkins, S.D. \& Howse, R. (2004). Individual differences in self-regulation: Implications for childhood adjustment. In P. Philipot \& R. Feldman (Eds.), The regulation of emotion. Mahwah, N.J. Lawrence Erlbaum.

Calkins, S. D., Smith, C. L., Gill, K. L., \& Johnson, M. C. (1998). Maternal interaction style across contexts: Relations to emotional, behavioral, and physiological regulation during toddlerhood. Social Development, 7, 350-369. doi: 10.1111/1467-9507.00072

Cameron, S. J., Snowdon, A., \& Orr, R. R. (1992). Emotions experienced by mothers of children with developmental disabilities. Childrens's Health Care, 21, 96-102. doi: $10.1207 / \mathrm{s} 15326888 \mathrm{chc} 2102 \_5$

Campbell-Sills, L., \& Barlow, D. H. (2006). Incorporating emotion regulation into conceptualizations and treatments of anxiety and mood disorders. In J.J. Gross (Ed.), Handbook of emotion regulation (pp. 542-559). New York: Guilford Press.

Carpenter, S., \& Halberstadt, A. G. (2000). Mothers' reports of events causing anger differ across family relationships. Social Development, 9, 458-477. doi: $10.1111 / 1467-9507.00138$

Carrère, S., \& Bowie, B. H. (2012). Like parent like child: Parent and child emotion dysregulation. Archives of Psychiatric Nursing, 0 (0), 1-8. Retrieved from http://www.seattleu.edu/uploadedFiles/Nursing/Directory/Carrere\%20and\%20Bowie2012-Like\%20Parent\%20Like\%20Child.pdf

Carstensen L. L., Gottman, J. M., \& Levenson, R. W. (1995). Emotional behavior in long-term marriage. Psychology and Aging, 10, 140-149. doi:10.1037/0882-7974.10.1.140 
Cassano, M., Perry-Parrish, C., \& Zeman, J. (2007). Influence of gender on parental socialization of children's sadness regulation. Social Development, 16(2), 210-231. doi: $10.1111 / \mathrm{j} .1467-9507.2007 .00381 . x$

Chang, L., Schwartz, D., Dodge, K. A., \& McBride-Chang, C. (2003). Harsh parenting in relation to child emotion regulation and aggression. Journal of Family Psychology, 17(4), 598-606. doi: 10.1037/0893-3200.17.4.598

Charles, S. T., \& Carstensen, L. L. (2013). Emotion regulation and aging. In J. J. Gross (Ed.), Handbook of Emotion Regulation (2nd Ed.). New York, NY: Guilford Press.

Cicchetti, D., Ganiban, J., \& Barnett, D. (1991). Contributions from the study of high risk populations to understanding the development of emotion regulation. In J. Garber \& K. A. Dodge (Eds.), The development of emotion regulation and dysregulation (pp. 15-48). New York: Cambridge University Press.

Cohen, J. (1988). Statistical power analysis for the behavioral sciences (2nd ed.).Hillsdale, NJ: Erlbaum.

Cole, P. M., Michel, M. K., \& Teti, L. O. (1994). The development of emotion regulation and dysregulation: A clinical perspective. Monographs of the Society for Research in Child Development, 59, (2-3), 73-100. doi: 10.1111/j.1540-5834.1994.tb01278.x

Cole, P. M., Teti, L. O., \& Zahn-Waxler, C. (2003). Mutual emotion regulation and the stability of conduct problems between preschool and early school age. Development and Psycholopathology, 15, 1-18. doi: 10.1017/S0954579403000014

Colpin, H., DeMunter, A., Nys, K., \& Vandemeulebroecke, L. (2000). Pre- and postnatal determinants of parenting stress in mothers of one-year-old twins. Marriage and Family Review, 30, 99-107. 
Colvin, A., Eyberg, S.M., \& Adams, C. (1999). Restandardization of the Eyberg Child Behavior Inventory. Gainesville: University of Florida, Child Study Laboratory. Retrieved from http://pcit.phhp.ufl.edu/Measures.htm

Coyne, J. C. \& Downey, G. (1991). Social Factors and Psychopathology: Stress, Social Support, and Coping Processes. Annual Review of Psychology, 42, 401-425. doi: 10.1146/annurev.ps.42.020191.002153

Creasey, G., \& Reese, M. (1996). Mothers' and fathers' perceptions of parenting hassles: Associations with psychological symptoms, nonparenting hassles, and child behavior problems. Journal of Applied Developmental Psychology, 17, 393-406. doi: 10.1016/S0193-3973(96)90033-7

Crnic, K. \& Greenberg, M. (1990). Minor parenting stress with young children. Child Development, 54, 209-217. doi: 10.2307/1129878

Cullenberg, J. (2003). Stressful life events preceding the first onset of psychosis. An explorative study. Nordic Journal of Psychiatry, 57(3), 209-214. doi: 10.1080/08039480310001373

Cummings, E. M., Keller, P. S., \& Davies, P. T. (2005). Towards a family process model of maternal and paternal depressive symptoms: Exploring multiple relations with child and family functioning. Journal of Child Psychology and Psychiatry, 46, 479-89. doi:10.1111/j.1469-7610.2004.00368.x

Davidov, M., \& Grusec, J. E. (2006). Untangling the links of parental responsiveness to distress and warmth to child outcomes. Child Development, 77, 44-58. doi: 10.1111/j.14678624.2006.00855.x 
Davidson, R., \& Irwin, W. (1999). The functional neuroanatomy of emotion and affective style. Trends in Cognitive Sciences, 3, 11-21. Retrieved from http://www.ncbi.nlm.nih.gov/pubmed/10234222

Davidson, R. J. (1999). Neuropsychological perspectives on affective styles and their cognitive consequences. In T. Dalgleish \& M. J. Power (Eds.), Handbook of cognition and emotion (pp. 103-123). New York: Wiley.

Davidson, R.J., Fox, A., \& Kalin, N. H. (2006). Neural bases of emotion regulation in nonhuman primates and humans. In J.J. Gross (Ed.), Handbook of emotion regulation (pp. 47-68). New York: Guilford Press.

Davies, P. T., Sturge-Apple, M. L., Cicchetti, D., Manning, L. G., \& Zale, E. (2009). Children's patterns of emotional reactivity to conflict as explanatory mechanisms in links between interpartner aggression and child physiological functioning. Journal of Child Psychology and Psychiatry, 50, 1384-1391. doi: 10.1111/j.1469-7610.2009.02154.x

Deater-Deckard, K. (2004). Parenting stress. New Haven, CT: Yale University Press.

De Bruyne, E., Van Hoecke, E., Van Gompel, K., Verbeken, S., Baeyens, D., Hoebeke, P., \& Vande Walle, J. (2009). Problem Behavior, Parental Stress and Enuresis. The Journal of Urology, 182, 2015-2021. doi: 10.1016/j.juro.2009.05.102

Denham, S. A., Mitchell-Copeland, J., Strandberg, K., Auerbach, S., \& Blair, K. (1997). Parental contributions to preschoolers' emotional competence: Direct and indirect effects. Motivation \& Emotion, 21, 65-86. doi: 10.1023/A:1024426431247 
Denham, S. A., Workman, E., Cole, P., Weissbrod, C., Kendziora, K., \& Zahn-Waxler, C. (2000). Parental contributions to externalizing and internalizing patterns in young children at risk for conduct disorder. Development and Psychopathology, 12, 23-45. doi: $10.1017 / \mathrm{S} 0954579400001024$

Denham, S. A., Zoller, D., \& Couchoud, E. A. (1994). Socialization of preschoolers' emotion understanding. Developmental Psychology, 30, 928-936. doi: $10.1037 / 0012-1649.30 .6 .928$

Diler, R. S., Birmaher, B., \& Miklowitz, D. J. (2010). Clinical presentation and longitudinal course of bipolar spectrum disorders in children and adolescents. In D. Miklowitz \& D. Cicchetti (Eds.), Understanding bipolar disorder: A developmental psychopathology perspective. (pp. 135-165). New York: The Guilford Press.

Dishion, T. J., French, D. C., \& Patterson, G. R. (1995). The development and ecology of antisocial behavior. In D. Cicchetti \& D. Cohen (Eds.), Manual of developmental psychopathology (pp. 421-471). New York: Wiley.

Dix, T. (1991). The affective organization of parenting: Adaptive and maladaptative processes. Psychological Bulletin, 110, 3-25. doi: 10.1037/0033-2909.110.1.3

Dodge, K. A., \& Coie, J. D. (1987). Social-information-processing factors in reactive and proactive aggression in children's peer groups. Journal of Personality and Social Psychology, 53, 1146-1158. doi:10.1037//0022-3514.53.6.1146

Dodge, K. A., Pettit, G. S., \& Bates, J. E. (1994). Socialization mediators of the relation between Socioeconomic status and child conduct problems, Child Development, 65, 649-665. 
Downey, G., \& Coyne, J. C. (1990). Children of depressed parents: An integrative review. Psychological bulletin, 108(1), 50-76. Retrieved from http://www.ncbi.nlm.nih.gov/pubmed/2200073

Dumas, J. E., LaFreniere, P. J., \& Serketich, W. J. (1995). "Balance of power”: A transactional analysis of control in mother-child dyads involving socially competent, aggressive, and anxious children. Journal of Abnormal Psychology, 104, 104-13. Retrieved from http://www.ncbi.nlm.nih.gov/pubmed/7897032

Dumas, J. E., Lemay, P., \& Dauwalder, J. P. (2001). Dynamic analyses of mother-child interactions in functional and dysfunctional dyads: A synergetic approach. Journal of Abnormal Child Psychology, 29, 317-29. Retrieved from http://www.ncbi.nlm.nih.gov/pubmed/11523837

Dunsmore, J. C., Booker, J. A, \& Ollendick, T. H. (2013). Parental emotion coaching and child emotion regulation as protective factors for children with Oppositional Defiant Disorder. Social Development 22, 444-466. doi:10.1111/j.1467-9507.2011.00652.x

Eddy, J. M., Leve, L. D., \& Fagot, B. I. (2001). Coercive family processes: A replication and extension of Patterson's Coercion Model. Aggressive Behavior, 27, 14-25. doi: 10.1002/1098-2337(20010101/31)27:1<14::AID-AB2>3.0.CO;2-2

Ehring, T., \& Quack, D. (2010). Emotion regulation difficulties in trauma survivors: The role of trauma type and PTSD symptom severity. Behavior Therapy, 41(4), 587-9. doi: $10.1016 /$ j.beth.2010.04.004

Eisenberg, N., \& Fabes, R. A. (1994). Mothers' reactions to children's negative emotions: Relations to children's temperament and anger behavior. Merrill-Palmer Quarterly, 40, $138-156$. 
Eisenberg, N., Sadovsky, A., Spinrad, T. L., Fabes, R. A, Losoya, S. H., Valiente, C., Reiser, M., et al. (2005). The relations of problem behavior status to children's negative emotionality, effortful control, and impulsivity: Concurrent relations and prediction of change. Developmental Psychology, 41, 193-211. doi:10.1037/0012-1649.41.1.193

Eisenberg, N., Fabes, R.A., Shepard, S. A., Guthrie, I. K., Murphy, B.C., \& Reiser, M. (1999). Parental reactions to children's negative emotions: Longitudinal relations to quality of children's social functioning. Child Development, 70, 513-534.

doi: $10.1111 / 1467-8624.00037$

Eisenberg, N., Hofer, C., \& Vaughan, J. (2007). Effortful control and its socioemotional consequences. In J. J. Gross (Ed.), Handbook of emotion regulation. New York: Guilford Press.

Eisenberg, N., \& Morris, A. S. (2002). Children's emotion-related regulation: Sharpening the definition. Child Development, 75, 334-339. doi: 10.1111/j.1467-8624.2004.00674.x

Emick, M. A., \& Hayslip, B. (1999). Custodial grandparenting: Stresses, coping skills, and relationships with grandchildren. The International Journal of Aging and Human Development, 48, 35-61. doi:10.2190/1FH2-AHWT-1Q3J-PC1K

Erath, S. A., Bierman, K. L. \& The Conduct Problems Prevention Research Group (2006). Aggressive marital conflict, maternal harsh punishment, and child aggressive-disruptive behavior: Evidence for direct and mediated relations. Journal of Family Psychology: Journal of the Division of Family Psychology of the American Psychological Association (Division 43), 20, 217-26. doi:10.1037/0893-3200.20.2.217

Eyberg, S.M., Nelson, M.M., Duke, M., \& Boggs, S.R. (2005). Manual for the parent-child interaction coding system $\left(3^{\text {rd }}\right.$ ed.). Retrieved February 25, 2013 from http://pcit.phhp.ufl.edu. 
Eyberg, S.M., \& Pincus, D. (1999). Eyberg Child Behavior Inventory and Sutter-Eyberg Student Behavior Inventory-Revised: Professional Manual. Odessa, FL: Psychological Assessment Resources.

Fabes, R.A., Eisenberg, N., \& Miller, P. (1990). Maternal correlates of children's vicarious emotional responsiveness. Developmental Psychology, 26, 639-648. doi: $10.1037 / 0012-1649.26 .4 .639$

Fabes, R. A., Leonard, S. A., Kupanoff, K., \& Martin, C. L. (2001). Parental Coping with Children's Negative Emotions: Relations with Children's Emotional and Social Responding. Child Development, 72(3), 907-920. doi: 10.1111/1467-8624.00323

Feng, X., Keenan, K., Hipwell, A. E., Henneberger, A. K., Rischall, M. S., Butch, J., Coyne, C., Boeldt, D., Hinze, A., \& Babinski, D. (2009). Longitudinal associations between emotion regulation and depression in preadolescent girls: Moderation by the caregiving environment. Developmental Psychology. 45, 798-808. doi: 10.1037/a0014617

Fernandez, M. A., Chase, R. M., Ingalls, C. A., \& Eyberg, S. M. (2006). The Abridged Workbook: Coder Training Manual for the Dyadic Parent-Child Interaction Coding System ( ${ }^{\text {rd }}$ ed.). Retrieved February 23, 2013 from http://pcit.phhp.ufl.edu.

Forgatch, M. S., \& Patterson, G. R. (2003). Parent management training - Oregon model: An intervention for antisocial behavior in children and adolescents. In A. E. Kazdin, \& J. R. Weisz (Eds.), Evidence-based psychotherapies for children and adolescents (pp. 241262). New York: Guilford Press.

Fox, H. C., Axelrod, S. R., Paliwal, P., Sleeper, J., \& Sinha, R. (2007). Difficulties in emotion regulation and impulse control during cocaine abstinence. Drug and Alcohol Dependence, 89, 298-301. doi: 10.1016/j.drugalcdep.2006.12.026 
Fox, H. C., Hong, K. A., \& Sinha, R. (2008). Difficulties in emotion regulation and impulse control in recently abstinent alcoholics compared with social drinkers. Addictive Behaviors, 33, 388-394. doi: 10.1016/j.addbeh.2007.10.002

Garber, J., Braafladt, N., \& Zeman, J. (1991). The regulation of sad affect: An informationprocessing perspective. In J. Garber \& K. A. Dodge (Eds.), The development of emotion regulation and dysregulation (pp. 208-240). New York, USA: Cambridge University Press.

Garnefski, N., \& Kraaj, V. (2007). The Cognitive Emotion Regulation Questionnaire: Psychometric features and prospective relationships with depression and anxiety in adults. European Journal of Psychological Assessment, 23(3), 141-149. doi: $10.1027 / 1015-5759.23 .3 .141$

Garside, R. B., \& Klimes-Dougan, B. (2002). Socialization of discrete negative emotions: Gender differences and links with psychological distress. Sex Roles, 47, 115-128. doi: 10.1023/A:1021090904785

Gauvain, M., \& Perez, S. M. (2008). Mother - child planning and child compliance. Child Development, 79, 761-775.

Goldsmith, H. H., Buss, K. A., \& Lemery, K. S. (1997). Toddler and childhood temperament: Expanded content, stronger genetic evidence, new evidence for the importance of environment. Developmental Psychology, 33, 891-905. doi: 10.1037/0012-1649.33.6.891

Gottman, J. M., \& Katz, L. F. (2002). Children's emotional reactions to stressful parent child interactions: The link between emotion regulation and vagal tone. Marriage \& Family Review, 34, 265-283. doi: 10.1300/J002v34n03_04 
Gratz, K. L., \& Roemer, L. (2004). Multidimensional assessment of emotion regulation and dysregulation: Development, factor structure, and initial validation of the Difficulties in Emotion Regulation Scale. Journal of Psychopathology and Behavioral Assessment, 26, 41-54. doi: 10.1023/B:JOBA.0000007455.08539.94

Gratz, K. L., \& Roemer, L. (2008). The relationship between emotion dysregulation and deliberate self-harm among female undergraduate students at an urban commuter university. Cognitive Behaviour Therapy, 37, 14-25. doi: 10.1080/16506070701819524

Gratz, K. L., Lacroce, D., \& Gunderson, J. G. (2006). Measuring changes in symptoms relevant to borderline personality disorder following short-term treatment across partial hospital and intensive outpatient levels of care. Journal of Psychiatric Practice, 12, 153-159. doi: 10.1097/00131746-200605000-00004

Gratz, K. L., \& Tull, M. T. (in press). Emotion regulation as a mechanism of change in acceptance-and mindfulness-based treatments. In R. A. Baer (Ed.), Assessing mindfulness and acceptance: Illuminating the process of change. Oakland, CA: New Harbinger Publications.

Graziano, P. A., Reavis, R. D., Keane, S. P., \& Calkins, S. D. (2007). The role of emotion regulation in children's early academic success. Journal of School Psychology, 45, 3-19. doi: $10.1016 /$ j.jsp.2006.09.002

Gross, J. J. (1998). Antecedent- and response-focused emotion regulation: Divergent consequences for experience, expression, and physiology. Journal of Personality and Social Psychology, 74, 224-237. doi: 10.1037/0022-3514.74.1.224 
Gross, J. J., \& John, O. P. (2003). Individual differences in two emotion regulation processes: Implications for affect, relationships, and well-being. Journal of Personality and Social Psychology, 85, 348-362. doi: 10.1037/0022-3514.85.2.348

Gross, J. J., \& Levenson, R.W. (1997). Hiding feelings: The acute effects of inhibiting positive and negative emotions. Journal of Abnormal Psychology, 106, 95-103. doi: 10.1037/0021-843X.106.1.95

Gross, J. J., \& Munoz, R. F. (1995). Emotion regulation and mental health. Clinical Psychology: Science and Practice, 2, 151-164. doi: 10.1111/j.1468-2850.1995.tb00036.x

Gross, J. J. (1999). Emotion and emotion regulation. In LA. Pervin \& O.P. John (Eds.), Handbook of personality: Theory and research ( $2^{\text {nd }}$ ed., pp. 525-552). New York: Guilford Press.

Gross, J. J., \& Thompson, R. A. (2007). Emotion regulation: Conceptual foundations. In J. J. Gross (Ed.), Handbook of emotion regulation (pp. 3-24). New York: Guilford Press.

Hammen, C. (2005). Stress and Depression. Annual Review of Clinical Psychology, 1, 293-319. doi: 10.1146/annurev.clinpsy.1.102803.143938

Harrison, A., Sullivan, S., Tchanturia, K., \& Treasure, J. (2009). Emotion recognition and regulation in anorexia nervosa. Clinical Psychology and Psychotherapy, 16, 348-356. doi: $10.1002 /$ cpp. 628

Hauser-Cram, P., Warfield, M. E., Shonkoff, J. P., \& Krauss, M. W. (2001). Children with disabilities: A longitudinal study of child development and parent well-being. Society for Research in Child Development, 66(3), 1-126. doi: 10.1111/1540-5834.00151 
Howes, P. W., Cicchetti, D., Toth, S. L., \& Rogosch, F. A. (2000). Affective, structural, and relational characteristics of maltreating families: A systems perspective. Journal of Family Psychology, 14, 95-110. doi: 10.1037/0893-3200.14.1.95

Jaffee, S. R., Caspi, A., Moffitt, T. E., \& Taylor, A. (2004). Physical maltreatment victim to antisocial child: Evidence of an environmentally mediated process. Journal of Abnormal Psychology, 113, (1), 44-55. doi: 10.1037/0021-843X.113.1.44

Joinson, C., Heron, J., von Gontard, A. Butler, U. Golding, J. \& Emond, A. (2008). Early childhood risk factors associated with daytime wetting and soiling in school-age children. Journal of Pediatric Psychology, 33(7), 739 -750. doi: 10.1093/jpepsy/jsn008

Joormann, J., \& D’Avanzato, C. (2010). Emotion regulation in depression: Examining the role of cognitive processes. Cognition and Emotion, 24, 913-939.

doi:10.1080/02699931003784939

Katz, L. F., \& Windecker-Nelson, B. (2004). Parental meta-emotion philosophy in families with conduct-problem children: Links with peer relations. Journal of Abnormal Child Psychology, 12, 385-398. doi: 10.1023/B:JACP.0000030292.36168.30

Keenan, K. \& Wakschlag, L. (2004). Are ODD and CD symptoms normative behaviors in preschoolers? A comparison of referred and non-referred children. American Journal of Psychiatry, 161, 356-358. doi: 10.1176/appi.ajp.161.2.356

Kessler, R. C. (1997). The effects of stressful life events on depression. Annual review of Psychology, 48, 191-214. doi: 10.1146/annurev.psych.48.1.191

Kessler, R. C., \& Magee, W. J. (1994). Childhood family violence and adult recurrent depression. The Journal of Health and Social Behavior, 35, 13-27. doi: 10.2307/2137332 
Kim, H. K., Pears, K. C., Capaldi, D. M., \& Owen, L. D. (2009). Emotion Dysregulation in the Intergenerational Transmission of Romantic Relationship Conflict. Journal of Family Psychology, 23 (4), 585-595. doi: 10.1037/a0015935

Kopp, C. (1989). Regulation of distress and negative emotions: A developmental view. Developmental Psychology, 25, 343-354. doi: 10.1037/0012-1649.25.3.343

Labouliere, C. D., (2009). The spectrum of self-harm in college undergraduates: The intersection of maladaptive coping and emotion dysregulation (2009). Graduate School Theses and Dissertations. Retrieved from http://scholarcommons.usf.edu/etd/2052

Lau, A. S., Valeri, S. M., McCarty, C. A, \& Weisz, J. R. (2006). Abusive parents' reports of child behavior problems: Relationship to observed parent-child interactions. Child Abuse \& Neglect, 30, 639-55. doi:10.1016/j.chiabu.2005.11.009

Lazarus, R. S. (1999). Stress and emotion: A new synthesis. New York: Springer.

Leahey, T., Crowther, J. H., \& Irwin, S. R. (2008). A cognitive-behavioral mindfulness group therapy intervention for the treatment of binge eating in bariatric surgery patients. Cognitive and Behavioral Practice, 15, 364-375. doi:

10.1016/j.cbpra.2008.01.004

Lindahl, K. M. (1998). Family process variables and children's disruptive behavior problems. Journal of Family Psychology, 12, 420-436. doi:10.1037//0893-3200.12.3.420

Linehan, M. M. (1998). An illustration of dialectical behavior therapy. In session: Psychotherapy in Practice, 4, 21-44.

doi: 10.1002/(SICI)1520-6572(199822)4:2<21::AID-SESS3>3.0.CO;2-B 
Lorber, M. F., \& O'Leary, S. G. (2005). Mediated paths to overreactive discipline: Mothers' experienced emotion, appraisals, and physiological responses. Journal of Consulting and Clinical Psychology, 73 (5), 971-981. doi: 10.1037/0022-006X.73.5.972

Loyd, B. H., \& Abidin, R. R. (1985). Revision of the Parenting Stress Index. Journal of Pediatric Psychology, 10,169-177. doi: 10.1093/jpepsy/10.2.169

Macklem, G. L. (2008). Parenting and emotion regulation. In G. L. Macklem (Ed.), Practitioner's guide to emotion regulation in school-aged children (pp. 49-61). New York: Springer.

Mammen, O. K., Kolko, D. J., \& Pilkonis, P. A. (2003). Parental cognitions and satisfaction: Relationship to aggressive parental behavior in child physical abuse. Child Maltreatment, 8, 288-301. doi: $10.1177 / 1077559503257112$

Mamorstein, N. R., \& Iacono, W. G. (2004). Major depression and conduct disorder in youth: Associations with parental psychopathology and parent-child conflict. Journal of child psychology and psychiatry, 45 (2), 377-386. doi: 10.1111/j.1469-7610.2004.00228.x

Marziali, E., Damianakis, T., \& Trocme, N. (2003). Nature and consequences of personality problems in maltreating caregivers. Families in Society: The Journal of Contemporary Human Services, 84, 530-538. Retrieved from http://www.mcgill.ca/crcf/sites/mcgill.ca.crcf/files/2003Personality_Problems_Maltreating_Caregivers.pdf

Mauss, I. B., Cook, C. L., \& Gross, J. J. (2007). Automatic emotion regulation during anger provocation. Journal of Experimental Social Psychology, 43, 698-711. doi: $10.1016 /$ j.jesp.2006.07.003 
Mazure, C. M. (2006). Life stressors as risk factors in depression. Clinical Psychology: Science and Practice, 5(3), 291-313. doi: 10.1111/j.1468-2850.1998.tb00151.x

McDowell, D. J., Kim, M., O.Neil, \& Parke, R. D. (2002). Children's emotional regulation and social competence in middle childhood: The role of maternal and paternal interactive style. Marriage \& Family Review, 34, 345-364. doi: 10.1300/J002v34n03_07

Melnick, S. M., \& Hinshaw, S. P. (2000). Emotion regulation and parenting in AD/HD and comparison boys: Linkages with social behaviors and preference. Journal of Abnormal Child Psychology, 28, 73-86. doi: 10.1023/A:1005174102794

Moffitt, T., et al. (2011). A gradient of childhood self-control predicts health, wealth, and public safety. Proceedings of the National Academy of Sciences, 108, 2693-2698.

doi: $10.1073 /$ pnas. 1010076108

Morison, M. J. (1998). Parents' and young people's attitude towards bedwetting and their influence on behavior including readiness to engage and persist with treatment. British Journal of Urology, 81(3), 56-66. doi: 10.1046/j.1464-410x.1998.00010.x

Murray, L., de Rosnay, M., Pearson, J., Bergeron, C., August, J., Rosnay, D., \& Pearson, J. (2014). Intergenerational transmission of social anxiety : The role of social referencing processes in infancy. Child Development, 79, 1049- 1064. doi: 10.1111/j.14678624.2008.01175.x

Morris, A. S., Silk, J. S., Steinberg, L., Myers, S. S., \& Robinson, L. R. (2007). The role of the family context in the development of emotion regulation. Social Development, 16, 361388. doi: 10.1111/j.1467-9507.2007.00389.x 
Muscatell, K. A., Slavich, G. M., Monroe, S. M., \& Gotlib, I. H. (2009). Stressful life events, chronic difficulties, and the symptoms of clinical depression. Journal of Nervous and Mental Disease, 197, 154-160. doi: 10.1097/NMD.0b013e318199f77b

Neumann, A., van Lier, P. A. C., Gratz, K. L., \& Koot, H. M. (2010). Multidimensional assessment of emotion regulation difficulties in adolescents using the Difficulties in Emotion Regulation Scale. Assessment, 17, 138-149. doi: 10.1177/1073191109349579

Paris, J., \& Zweig-Frank, H. (2001). A 27-year follow-up of patients with borderline personality disorder. Comprehensive psychiatry, 42, 482-7. doi:10.1053/comp.2001.26271

Parpal, M., \& Maccoby, E. E. (1985). Maternal responsiveness and subsequent child compliance. Child Development, 56, 1326-1334.

Perez, J., Venta, A., Garnaat, S., \& Sharp, C. (2012). The difficulties in emotion regulation scale: Factor structure and association with nonsuicidal self-injury in adolescent inpatients. Journal of Psychopathology and Behavioral Assessment, 34(3). 393404. doi: 10.1007/s10862-012-9292-7

Reeb, B. T., Conger, K. J., \& Wu, E. Y. (2010). Paternal depressive symptoms and adolescent functioning: The moderating effect of gender and father hostility. Fathering, 8, 131-142. doi: 10.3149/fth.0801.131

Robinson, E. A., \& Eyberg, S. M. (1981). The Dyadic Parent-Child Interaction Coding System: Standardization and validation. Journal of Consulting and Clinical Psychology, 49, 245250. doi: 10.1037/0022-006X.49.2.245 
Roemer, L., Lee, J. K., Salters-Pedneault, K., Erisman, S. M., Orsillo, S. M., \& Mennin, D. S. (2009). Mindfulness and emotion regulation difficulties in generalized anxiety disorder: Preliminary evidence for independent and overlapping contributions. Behavior Therapy, 40, 142-154. doi: 10.1016/j.beth.2008.04.001

Rogosch, F. A., Cicchetti, D., \& Toth, S. L. (2004). Expressed emotion in multiple subsystems of the families of toddlers with depressed mothers. Development and Psychopathology, 6(3), 689-709. doi: 10.1017/S0954579404004730

Röll, J., Koglin, U., \& Petermann, F. (2012). Emotion regulation and childhood aggression: Longitudinal associations. Child Psychiatry and Human Development, 43, 909-23. doi:10.1007/s10578-012-0303-4'

Salmon, K., Dadds, M., Allen, J., Hawes, D. (2009). Can emotional language skills be taught during parent training for conduct problem children? Child Psychiatry and Human Development, 40, 485-498.

Schmitz, S., Fulker, D. W., Plomin, R., Zahn-Waxler, C., \& DeFries, J. C. (1999). Temperament and problem behavior during early childhood. International Journal of Behavioral Development, 23, 333-355. doi 10.1080/016502599383856

Shaw, D.S., Keenan, K., Vondra, J.I., Delliquadri, E., \& Giovannelli, J. (1997). Antecedents of preschool children's internalizing problems: A longitudinal study of low-income families. Journal of the American Academy of Child and Adolescent Psychiatry, 36, 1760-1767.

Shields, A., \& Cicchetti, D. (1997). Emotion regulation among school-age children: the development and validation of a new criterion q-sort scale. Developmental Psychology, 33, 906-916. doi: 10.1037/0012-1649.33.6.906 
Shields, A., \& Cicchetti, D. (1998). Reactive aggression among maltreated children: The contributions of attention and emotion dysregulation. Journal of Clinical Child Psychology, 27, 381-395. doi: 10.1207/s15374424jccp2704_2

Shipman, K., \& Zeman, J. (2001). Socialization of children's emotion regulation in mother-child dyads: A developmental psychopathology perspective. Development and Psychopathology, 13, 317-336. doi: 10.1017/S0954579401002073

Shipman, K., Schneider, R. Fitzgerald, M. M., Sims, C. Swisher, L., \& Edwards, A. (2007). Maternal socialization in maltreating and nonmaltreating families: Implications for children's emotion regulation. Social Development, 16, 203-209. doi: 10.1111/j.14679507.2007.00384.x

Sloan, R. P., Bagiella, E., Shapiro, P. A., Kuhl, J. P., Chernikhova, D., Berg, J. \& Myers, M. M. (2001). Hostility, gender and cardiac autonomic control. Psychosomatic Medicine, 63, 434-440. Retrieved from http://www.psychosomaticmedicine.org/content/63/3/434.full.pdf

Stringaris, A., \& Goodman, R. (2009). Three dimensions of oppositionality in youth. Journal of child psychology and psychiatry, and allied disciplines, 50, 216-23. doi:10.1111/j.14697610.2008.01989.x

Stringaris, A., Maughan, B., \& Goodman, R. (2010). What's in a Disruptive Disorder? Temperamental antecedents of Oppositional Defiant Disorder: Findings from the Avon Longitudinal Study. Journal of the American Academy of Child \& Adolescent Psychiatry, 49, 474-483. doi:10.1016/j.jaac.2010.01.021 
Suveg, C., Jacob, M. L., \& Payne, M. (2010). Parental interpersonal sensitivity and youth social problems: A meditational role for child emotion dysregulation. Journal of Child and Family Studies, 19, 677-686. doi: 10.1007/s10826-010-9354-y

Suveg, C., \& Zeman, J. (2004). Emotion regulation in children with anxiety disorders. Journal of Clinical Child and Adolescent Psychology, 33, 750-759. doi: 10.1207/s15374424jccp3304_10

Thompson, R. A. (1991). Emotional regulation and emotional development. Educational Psychology Review, 3, 269-307. doi: 10.1007/BF01319934

Thompson, R. A. (1994). Emotion regulation: A theme in search of definition. In N. A. Fox (Ed.), The development of emotion regulation: Biological and behavioral considerations, Monographs of the Society for Research in Child Development, 59(2/3), 25-52. Chicago, Ill.

Thompson, R. A. \& Meyer, S. (2006). Socialization of emotion regulation in the family. In J.J. Gross (Ed.), Handbook of emotion regulation (pp. 249-268). New York: Guilford Press.

Uliaszek, A. A., Zinbarg, R. E., Mineka, S., Craske, M. G., Griffith, J. W., Sutton, J. M., Epstein, A., \& Hammen, C. (2012). A Longitudinal Examination of Stress Generation in Depressive and Anxiety Disorders. Journal of Abnormal Psychology, 121, (1), 4-15. doi: $10.1037 / \mathrm{a} 0025835$

Umberson, D., Wortman, C. B., \& Kessler, R. C. (1992). Widowhood and depression: explaining long-term gender differences in vulnerability. The Journal of Health and Social Behavior, 33, 10-24. doi: $10.2307 / 2136854$ 
Vettese, L. C., Dyer, C. E., Li W. L. \& Wekerle, C. (2011). Does self-compassion mitigate the association between childhood maltreatment and later emotional regulation difficulties? A preliminary investigation. International Journal of Mental Health and Addiction, 9, 480-491. doi: 10.1007/s11469-011-9340-7

Walsh, K., DiLillo, D. K., \& Scalora, M. J. (2011). The cumulative impact on emotion regulation difficulties: An examination of female inmates. Violence against Women, 17 (8): $1103-$ 1118. doi: $10.1177 / 1077801211414165$

Wang, M., \& Saudino, K. J. (2011). Emotion regulation and stress. Journal of Adult Development, 18(2), 95-103. doi:10.1007/s10804-010-9114-7

Watts, F. (2006). Emotion regulation and religion. In J.J. Gross (Ed.), Handbook of emotion regulation (pp. 504-522). New York: Guilford Press.

Watkins, E., \& Brown, R. G. (2002). Rumination and executive function in depression: An experimental study. Journal of Neurology, Neurosurgery and Psychiatry, 72 (3), 400-402. doi: $10.1136 /$ jnnp.72.3.400

Webster-Stratton, C., \& Eyberg, S. M. (1982). Child temperament: Relationship with child behavior problems and parent-child interactions. Journal of Clinical Child Psychology, 1 (2), 123-129. Retrieved from http://www.son.washington.edu/centers/parentingclinic/opendocs/Child\%20temperament1982.pdf

Whaley, S. E., Pinto, a, \& Sigman, M. (1999). Characterizing interactions between anxious mothers and their children. Journal of consulting and clinical psychology, 67(6), 826-36. Retrieved from http://www.ncbi.nlm.nih.gov/pubmed/10596505 
Williford, A. P., Calkins, S. D., \& Keane, S. P. (2007). Predicting change in parenting stress across early childhood: Child and maternal factors. Journal of Abnormal Child Psychology, 35, 251-63. doi:10.1007/s10802-006-9082-3

Zawadzki, B., Strelau, J., Oniszcenko, W., Riemann, R., \& Angleitner, A. (2001). Genetic and environmental influences on temperament: The Polish-German twin study, based on selfreport and peer-rating. European Psychologist, 6(4), 272-286. doi:10.1027//10169040.6 .4 .272

Zimmermann, L. K., \& Stansbury, K. (2004). The influence of emotion regulation, level of shyness, and habituation on the neuroendocrine response of three-year-old children. Psychoneuroendocrinology, 29, 973-82. doi:10.1016/j.psyneuen.2003.09.003 
Table 1

Means and Standard Deviations for Caregiver, Child Age and Family Income

\begin{tabular}{lll}
\hline Demographic Variable & $\mathrm{M}$ & $\mathrm{SD}$ \\
\hline Caregiver age (in years) & 32.59 & 8.53 \\
Child age (in years) & 5.39 & 1.27 \\
Family income $^{\mathrm{a}}$ & $\$ 42,183$ & $\$ 60,277$ \\
\hline
\end{tabular}

Note. ${ }^{a} n=29$ 
Table 2

Count of Caregiver Marital Status

\begin{tabular}{lc}
\hline Marital Status & Caregiver \\
\hline Married & $12(38 \%)$ \\
Living with a partner & $9(28 \%)$ \\
Separated & $1(3 \%)$ \\
Divorced & $2(6 \%)$ \\
Never Married & $6(19 \%)$ \\
Other & $2(6 \%)$ \\
\hline
\end{tabular}


Table 3

Count of Caregiver and Child Sex and Race

\begin{tabular}{lcc}
\hline & Caregiver & Child \\
\hline Gender & $3(9.4 \%)$ & $24(75 \%)$ \\
Male & $29(90.6 \%)$ & $8(25 \%$ \\
Female & & \\
Race & $27(84.4 \%)$ & $23(71.9 \%)$ \\
Caucasian & $4(12.5 \%)$ & $6(18.8 \%)$ \\
African American & 0 & 0 \\
Hispanic & 0 & 0 \\
Asian & $1(3.1 \%)$ & $3(9.4 \%)$ \\
Mixed or "other" &
\end{tabular}


Table 4

Count of Highest Caregiver Educational Level Achieved

\begin{tabular}{ll}
\hline & Caregiver \\
\hline Education & \\
Some High School & $4(13 \%)$ \\
High School Diploma/G.E.D. & $8(25 \%)$ \\
Some College & $7(22 \%)$ \\
Associates Degree & $6(19 \%)$ \\
Bachelor's Degree & $1(3 \%)$ \\
Some Graduate School & $2(6 \%)$ \\
Master's Degree & $3(9 \%)$ \\
Doctoral Degree & $1(3 \%)$ \\
\hline
\end{tabular}




\section{Table 5}

Means and Standard Deviations for Emotion Regulation Measures in a Non-Referred Comparison Adult Sample, Non-Referred Comparison Child Sample and Current Sample of Caregivers and Children

\begin{tabular}{lccccccc}
\hline & \multicolumn{3}{c}{ Comparison Sample } & & \multicolumn{3}{c}{ Current Sample } \\
\cline { 2 - 6 } \cline { 5 - 7 } & $\mathrm{n}$ & $\mathrm{M}$ & $\mathrm{SD}$ & $\mathrm{n}$ & $\mathrm{M}$ & $\mathrm{SD}$ \\
DERS Total Score $^{\mathrm{a}}$ & 357 & 78.72 & not available & 32 & 72.38 & 21.45 \\
ERC Emotion Regulation $^{\mathrm{b}}$ & 236 & 3.33 & .33 & 32 & 3.12 & .33 \\
ERC Lability/Negativity $^{\mathrm{c}}$ & 236 & 1.91 & .39 & 32 & 2.55 & .56 \\
\hline
\end{tabular}

Note. ${ }^{a}$ Higher scores on the Difficulties in Emotion Regulation Scale (DERS) indicate greater difficulty with emotion regulation, ${ }^{\mathrm{b}}$ Higher scores on the Emotion Regulation Checklist (ERC) Emotion Regulation subscale indicate better emotion regulation, ${ }^{\mathrm{c}}$ Higher scores on the ERC Lability/Negativity subscale indicate higher levels of lability/negativity. 
Table 6

Results of One-sample t-test for Emotion Regulation Measures

\begin{tabular}{|c|c|c|c|c|c|}
\hline ERC Subscale & $\begin{array}{c}\text { Comparison } \\
\text { Value }\end{array}$ & $\begin{array}{c}95 \% \text { CI for Mean } \\
\text { Difference }\end{array}$ & $\mathrm{t}$ & $\mathrm{p}$ & $\mathrm{df}$ \\
\hline DERS $^{\mathrm{a}}$ Total Score & 78.72 & $-.14 .08, .1 .39$ & -1.673 & .104 & 31 \\
\hline $\begin{array}{l}\text { ERC }^{b} \text { Emotion } \\
\text { Regulation }\end{array}$ & 3.33 & $-.3306, .-.0950$ & -3.684 & $.001 * *$ & 31 \\
\hline ERC Lability/Negativity & 1.91 & $.4440, .8444$ & 6.562 & $.000 * *$ & 31 \\
\hline
\end{tabular}

Note. ${ }^{\mathrm{a} D i f f i c u l t i e s ~ i n ~ E m o t i o n ~ R e g u l a t i o n ~ S c a l e ~(D E R S), ~}{ }^{\mathrm{b}}$ Emotion Regulation Checklist (ERC). 
Table 7

Means and Standard Deviations for Parent Measures Total Scores and Subscale Scores

\begin{tabular}{|c|c|c|}
\hline Measure & M & SD \\
\hline DERS $^{\mathrm{a}}$ Total Score & 72.38 & 21.45 \\
\hline DERS Non-acceptance of emotional responses & 11.09 & 5.04 \\
\hline $\begin{array}{l}\text { DERS Difficulties engaging in goal directed } \\
\text { behavior }\end{array}$ & 13.25 & 5.84 \\
\hline DERS Impulse control difficulties & 10.59 & 5.03 \\
\hline DERS Lack of emotional awareness & 13.91 & 3.78 \\
\hline $\begin{array}{l}\text { DERS Limited access to emotion regulation } \\
\text { strategies }\end{array}$ & 14.59 & 6.67 \\
\hline DERS Lack of emotional clarity & 8.94 & 3.31 \\
\hline PSI $^{\mathrm{b}}$ Total Score & 87.94 & 23.20 \\
\hline PSI Parental Distress & 28.19 & 10.05 \\
\hline PSI Parent-Child Dysfunctional Interaction & 23.09 & 6.74 \\
\hline PSI Difficult Child & 36.66 & 10.11 \\
\hline $\mathrm{CBCL}^{\mathrm{c}}$ Internalizing Score & 12.31 & 8.70 \\
\hline CBCL Externalizing Score & 24.84 & 10.87 \\
\hline CBCL Total Score & 58.88 & 26.77 \\
\hline $\mathrm{ECBI}^{\mathrm{d}}$ Intensity Score & 149.81 & 44.72 \\
\hline ECBI Problem Score & 19.16 & 7.97 \\
\hline DPICS $^{\mathrm{e}}$ Compliance Composite & .34 & .18 \\
\hline DPICS Negative Talk & 12.00 & 15.65 \\
\hline ERC ${ }^{\mathrm{f}}$ Total Score & 2.68 & .42 \\
\hline
\end{tabular}

Note. ${ }^{\mathrm{a}}$ Difficulties in Emotion Regulation Scale (DERS), ${ }^{\mathrm{b}}$ Parenting Stress Index (PSI), ${ }^{\mathrm{c}}$ Child Behavior Checklist (CBCL), ${ }^{\mathrm{d}}$ Eyberg Child Behavior Inventory (ECBI), ${ }^{\mathrm{e}}$ Dyadic Parent Child Interaction Coding System (DPICS), ${ }^{\mathrm{f}}$ Emotion Regulation Checklist (ERC). 
Table 8

Correlations between DERS Total Score and PSI Total and Subscale Scores

\begin{tabular}{llc}
\hline & DERS Total Score & $\mathrm{p}$ \\
\hline PSI $^{\mathrm{a}}$ Total Score & $.654^{* *}$ & .000 \\
Parent Distress & $.776^{* *}$ & .000 \\
Parent-Child Dysfunctional & $.497^{* *}$ & .004 \\
Interaction & & \\
Difficult Child & $.398^{*}$ & .024 \\
\hline
\end{tabular}

$* \mathrm{p}<.05 . * * \mathrm{p}<.01$

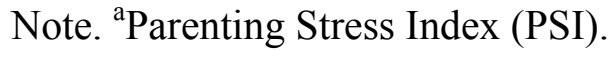


Table 9

Correlations between DERS total score and CBCL Subscale Scores

\begin{tabular}{ll}
\hline & DERS Total Score \\
\hline CBCL $^{\text {a }}$ Internalizing & $.439^{*}$ \\
CBCL Externalizing & $.396^{*}$ \\
CBCL Total Score & $.512^{* *}$ \\
\hline
\end{tabular}

${ }^{*} \mathrm{p}<.05 .{ }^{*} \mathrm{p}<.01$

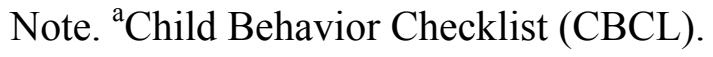


Table 10

Correlations between DERS total score and ECBI Subscale Scores

\begin{tabular}{llc}
\hline & DERS Total Score & $\mathrm{p}$ \\
\hline ECBI $^{\mathrm{a}}$ Intensity & .337 & .060 \\
ECBI Problem & .284 & .116 \\
\hline
\end{tabular}

Note. ${ }^{\mathrm{a}}$ Eyberg Child Behavior Inventory (ECBI). 
Table 11

Correlation between DERS total score and ERC Total Score

\begin{tabular}{llc}
\hline & DERS Total Score & $\mathrm{p}$ \\
\hline ERC $^{\mathrm{a}}$ Total Score & -.253 & .163 \\
ERC & .276 & .127 \\
Lability/Negativity & & \\
ERC Emotion & -.058 & .754 \\
Regulation & & \\
\hline
\end{tabular}

Note. ${ }^{a}$ Emotion Regulation Checklist (ERC). 
Table 12

Summary of Linear Multiple Regression Analysis Predicting Caregiver Emotion Dysregulation (DERS)

\begin{tabular}{|c|c|c|c|c|c|c|}
\hline Variable & $\mathrm{B}$ & $\beta$ & $\mathrm{t}$ & Sig. (p) & Tolerance & VIF \\
\hline $\begin{array}{l}\text { PSI }^{\mathrm{a}} \text { Parental } \\
\text { Distress } \\
\text { Subscale }\end{array}$ & 1.593 & .747 & 4.494 & $.000^{* *}$ & .517 & 1.935 \\
\hline $\begin{array}{l}\text { CBCL }^{b} \text { Total } \\
\text { Score }\end{array}$ & .119 & .148 & .623 & .539 & .251 & 3.982 \\
\hline $\log 10$ DPICS $^{\mathrm{c}}$ & & & & & & \\
\hline Negative Talk & 4.818 & .109 & .897 & .378 & .957 & 1.045 \\
\hline $\begin{array}{l}\mathrm{ECBI}^{\mathrm{d}} \text { Intensity } \\
\text { Score }\end{array}$ & -.017 & -.035 & -.161 & .873 & .295 & 3.390 \\
\hline $\begin{array}{l}\text { ERC }^{\mathrm{e}} \text { Total } \\
\text { Score }\end{array}$ & 8.678 & .169 & .742 & .465 & .275 & 3.633 \\
\hline
\end{tabular}

Note. ${ }^{\mathrm{a} P a r e n t i n g ~ S t r e s s ~ I n d e x ~(P S I), ~}{ }^{\mathrm{b}}$ Child Behavior Checklist (CBCL), ${ }^{\mathrm{c} D y a d i c}$ Parent Child Interaction Coding System (DPICS), ${ }^{\mathrm{d}}$ Eyberg Child Behavior Inventory (ECBI), ${ }^{\mathrm{e}}$ Emotion Regulation Checklist (ERC). 
Table 13

Summary of Linear Multiple Regression Analysis Predicting Child Emotion Regulation (ERC)

\begin{tabular}{|c|c|c|c|c|c|c|}
\hline Variable & B & $\beta$ & $\mathrm{t}$ & Sig. (p) & Tolerance & VIF \\
\hline DERS $^{\mathrm{a}}$ Total Score & .002 & .123 & .742 & .465 & .379 & 2.641 \\
\hline $\begin{array}{l}\mathrm{PSI}^{\mathrm{b}} \text { Parental } \\
\text { Distress Subscale } \\
\text { Score }\end{array}$ & .003 & .064 & .340 & .737 & .292 & 3.424 \\
\hline $\mathrm{CBCL}^{\mathrm{c}}$ Total Score & -.007 & -.480 & -2.644 & $.014^{*}$ & .314 & 3.185 \\
\hline $\begin{array}{l}\text { Log } 10 \text { DPICS }^{\mathrm{d}} \\
\text { Negative Talk }\end{array}$ & -.019 & -.022 & -.210 & .835 & .929 & 1.076 \\
\hline $\begin{array}{l}\mathrm{ECBI}^{\mathrm{e}} \text { Intensity } \\
\text { Score }\end{array}$ & -.005 & -.516 & -3.265 & $.003 *$ & .416 & 2.406 \\
\hline
\end{tabular}

Note. ${ }^{a}$ Difficulties in Emotion Regulation Scale (DERS), ${ }^{\mathrm{b}}$ Parenting Stress Index (PSI), ${ }^{\mathrm{c}}$ Child

Behavior Checklist (CBCL), ${ }^{\mathrm{d}}$ Dyadic Parent Child Interaction Coding System (DPICS), ${ }^{\mathrm{e}}$ Eyberg Child Behavior Inventory (ECBI), ${ }^{\mathrm{f}}$ Emotion Regulation Checklist (ERC). 
Table 14

Correlational Matrix between all Total Scores

\begin{tabular}{|c|c|c|c|c|c|c|c|c|}
\hline Variable & 1 & 2 & 3 & 4 & 5 & 6 & 7 & 8 \\
\hline $\begin{array}{l}\text { 1. DERS } \\
\text { Total Score }\end{array}$ & - & & & & & & & \\
\hline $\begin{array}{l}\text { 2. } \mathrm{CBCL}^{\mathrm{b}} \\
\text { Total Score }\end{array}$ & $.512 * *$ & - & & & & & & \\
\hline $\begin{array}{l}\text { 3. } \text { PSI }^{\mathrm{c}} \\
\text { Total Score }\end{array}$ & $.654 * *$ & $.704 * *$ & - & & & & & \\
\hline $\begin{array}{l}\text { 4. } \mathrm{ECBI}^{\mathrm{d}} \\
\text { Intensity } \\
\text { Score }\end{array}$ & .337 & $.759 * *$ & $.685^{* *}$ & - & & & & \\
\hline $\begin{array}{l}\text { 5. ECBI } \\
\text { Problem } \\
\text { Score }\end{array}$ & .284 & $.587 * *$ & $.638 * *$ & $.823^{* *}$ & - & & & \\
\hline $\begin{array}{l}\text { 6. ERC } \\
\text { Total Score }\end{array}$ & -.253 & $-.770 * *$ & $-.632 * *$ & $-.808 * *$ & $-.596^{* *}$ & - & & \\
\hline $\begin{array}{l}\text { 7. DPICS } \\
\text { Compliance }\end{array}$ & -.158 & -.059 & .011 & -.227 & -.250 & .021 & - & \\
\hline $\begin{array}{l}\text { 8. DPICS } \\
\text { Negative } \\
\text { Talk }\end{array}$ & .258 & .172 & .140 & .101 & .078 & -.113 & -.241 & - \\
\hline
\end{tabular}

Note. ${ }^{\mathrm{a} D i f f i c u l t i e s ~ i n ~ E m o t i o n ~ R e g u l a t i o n ~ S c a l e ~(D E R S), ~}{ }^{\mathrm{b}}$ Child Behavior Checklist (CBCL),

${ }^{\mathrm{c}}$ Parenting Stress Index (PSI), ${ }^{\mathrm{d}}$ Eyberg Child Behavior Inventory (ECBI), ${ }^{\mathrm{e}}$ Emotion Regulation

Checklist (ERC) ${ }^{\mathrm{f}}$ Dyadic Parent Child Interaction Coding System (DPICS). 
